IZA DP No. 9575

The Effectiveness of Early Vacancy Information in the Presence of Monitoring and ALMP

Ricarda Schmidl

December 2015 


\title{
The Effectiveness of Early Vacancy Information in the Presence of Monitoring and ALMP
}

\author{
Ricarda Schmidl \\ University of Mannheim \\ and IZA
}

\section{Discussion Paper No. 9575 \\ December 2015}

\author{
IZA \\ P.O. Box 7240 \\ 53072 Bonn \\ Germany \\ Phone: +49-228-3894-0 \\ Fax: +49-228-3894-180 \\ E-mail: iza@iza.org
}

Any opinions expressed here are those of the author(s) and not those of IZA. Research published in this series may include views on policy, but the institute itself takes no institutional policy positions. The IZA research network is committed to the IZA Guiding Principles of Research Integrity.

The Institute for the Study of Labor (IZA) in Bonn is a local and virtual international research center and a place of communication between science, politics and business. IZA is an independent nonprofit organization supported by Deutsche Post Foundation. The center is associated with the University of Bonn and offers a stimulating research environment through its international network, workshops and conferences, data service, project support, research visits and doctoral program. IZA engages in (i) original and internationally competitive research in all fields of labor economics, (ii) development of policy concepts, and (iii) dissemination of research results and concepts to the interested public.

IZA Discussion Papers often represent preliminary work and are circulated to encourage discussion. Citation of such a paper should account for its provisional character. A revised version may be available directly from the author. 


\section{ABSTRACT \\ The Effectiveness of Early Vacancy Information in the Presence of Monitoring and ALMP*}

This paper studies the effectiveness of vacancy information from the public employment services (PES) in Germany, focussing on vacancy information obtained early in the unemployment spell. As in many other countries, the German activation practice combines information provision with monitoring to increase the willingness to apply. In case of a failed application, unemployed may participate in more intensive active labor market programs (ALMP). Exposure to monitoring or participation in ALMP is likely to confound the effect of information; our aim is to disentangle the different effects. Based on a flexible propensity score matching approach, we find that vacancy information increases the entry rate into unemployment predominantly by jobs mediated via the PES. Monitoring seems to reinforce this effect while limiting the crowding out of transitions made through other channels. In case of continued unemployment, early vacancy information reduces the participation rate in ALMP for some labor market groups. This is however not found to mediate the effect on employment transitions. We hence suggest that early vacancy information may increase the cost-effectiveness of the overall activation process even in the case of unsuccessful applications. Slight negative effects on employment quality seem to be driven by a combination of vacancy quality and monitoring.

JEL Classification: J08, J64

Keywords: unemployment, vacancy information, public employment services, active labor market programs

Corresponding author:

Ricarda Schmidl

Department of Economics

University of Mannheim

L7, 3-5

68131 Mannheim

Germany

E-mail: schmidl@uni-mannheim.de

\footnotetext{
* I thank Arne Uhlendorff and Johan Vikström as well as participants at the seminar in Potsdam, the EEA, the EALE and the COMPIE conference for valuable comments. This study uses the IZA ED Survey as provided by the International Data Service Center (IDSC) of the Institute for the Study of Labor (IZA). Financial Support of the Deutsche Post Foundation as well as the SFB 884 by the German Research Foundation are gratefully acknowledged. The usual disclaimer applies.
} 


\section{Introduction}

To activate the unemployed, the public employment services (PES) usually rely on a mix of activation instruments. Mediation services - defined as the transmission of vacancy information and providing support in the application process - commonly constitute the 'baseline' strategy (for more details on the activation mix employed by different countries, see OECD, 2007). Germany is a typical example where vacancy information, job search monitoring and active labor market programs (ALMP) are administered at the PES and used jointly to promote employment entry of the unemployed. The discussion of vacancy information is typically given a special emphasis in the first meetings between the caseworker and the unemployed (Schütz et al., 2011). As counseling and information provision is less expensive than participation in intensive training programs, this is intended to reduce the cost of activation. From an efficiency perspective the early focus on information may also be optimal. If duration dependence reduces the job offer probability over the course of unemployment (see, e.g., van den Berg, 1994; van den Berg and van Ours, 1996; Machin and Manning, 1999), the benefit of information is expected to be highest early on.

In the outlined activation practice, other activation instruments may interact with early information provision, thus complicating an assessment of the direct employment effects. In particular, while simultaneous monitoring is intended to increase the willingness of unemployed to apply to and accept jobs from the PES, more intensive ALMP programs may be used in case where information did not result in successful labor market transition. So far only little evidence is available on the benefits of early vacancy information for employment entry in the presence of alternative instruments. We aim to fill this gap by studying the effectiveness of early vacancy receipt from the PES in Germany.

Previous analyses of the effectiveness of vacancy information with or without monitoring suggest that the effect of vacancy information on employment transition rates is ambiguous. Fougère, Pradel, and Roger (2009) find that without monitoring vacancy information increases the productivity of PES search, but reduces the search effort in other channels, thus counteracting the information effect. Van den Berg and van der Klaauw (2006) assess the effects of combining counseling with monitoring to counteract the effort substitution. They show that monitoring may be completely ineffective if it focusses on only a subset of search channels, as unemployed may be forced to invest search in low rather than high productivity channels. Engström, 
Hesselius, and Holmlund (2012) find no effect of announcing an increased monitoring intensity for vacancy applications, suggesting that this may be due to an incredible monitoring threat and the substitution effect. Gorter and Kalb (1996) find that a counseling and monitoring increases the number of applications sent out, but not the acceptance rate, resulting in an overall zero employment effect. Johnson and Klepinger (1994), Dolton and O'Neill (2002) and Hägglund (2014) in contrast find significant positive effects of the combinations of counseling and monitoring. An recent empirical analysis by van den Berg, Hofmann, and Uhlendorff (2013) shows that vacancy receivers in Germany exit unemployment more quickly. They find that monitoring may drive part of the employment exit, as vacancies also increase the risk of sanctions and entry into sickness absence.

Both monitoring and information may affect the job match quality. Understanding their relative contribution to the overall employment effect is thus important to adequately address the source of quality differences. Johnson and Klepinger (1994) and Dolton and O'Neill (2002) exploit experimental variation in the exposure to either component during job search and conclude that it is mostly the threat effect driving the exit rate from unemployment. In the regular activation practice, the monitoring component of vacancy information is usually not observed, however. We thus aim to disentangle the role of simultaneous job search monitoring based on job search theoretic predictions on channel-specific transition rates with or without monitoring. Comparing these predictions with observation of the successful search channel we assess whether monitoring contributes to employment transitions.

The interaction between early information or counseling and subsequent ALMP participation has not been studied so far. ${ }^{1}$ Against the findings of van den Berg et al. (2013), it seems plausible however that monitored vacancy information may act as a screening device for the caseworker. This may in turn affect the subsequent use of activation instruments. While the observation of application effort may provide signals about the willingness of unemployed to cooperate with search requirements, observing the application outcome may also convey information about specific hurdles to labor market integration. Similarly, if caseworker are initially uncertain about the labor market chances of the unemployed, vacancy availability alone may signal better expected labor market chances. Thus, even in absence of direct employment effects, vacancy information may affect the subsequent activation path, and thereby indi-

\footnotetext{
${ }^{1}$ The threat effect arising from the anticipated ALMP participation at later stages of unemployment is studied by, e.g., (Graversen and van Ours, 2008; Pedersen, Rosholm, and Svarer, 2012)
} 
rectly affect unemployment reintegration. Using information on the ALMP entries, we document the effects of vacancy information on participation rates in ALMP, and assess whether this contributes to the employment transitions due to early vacancies. Exploiting information on early activation offers, ex-ante differences in anticipated ALMP participation, arising due to unobserved characteristics of the caseworker or the unemployed can be controlled for.

The empirical analysis makes use of a representative survey of unemployment entrants between 2007 and 2008, the IZA Evaluation Dataset Survey (Caliendo et al., 2011). The survey consists of an extensive baseline interview conducted shortly after unemployment entry and a follow-up interview one year later, collecting the subsequent labor market outcomes including participation in ALMP. In addition to capturing labor market relevant characteristics, the baseline survey collects detailed information on the job search behavior of the unemployed, as well as information on activation offers made by the PES. Regional indicators allow to merge information on local labor market conditions and activation practices at the PES level. Given the detail of the survey data with respect to the relevant characteristics, we adopt a semi-parametric matching approach (Rosenbaum and Rubin, 1983) assuming conditional independence of vacancy receipt and the transitions in employment and more intensive ALMP. To disentangle the effects of vacancy information and ALMP participation, we use the sequence of treatment estimator proposed by Vikström (2015) that takes into account the dynamic nature of entry into ALMP.

We find that early vacancy receipt increases early employment take-up significantly. After one year, the employment gap between treated and controls is still at 7\%-points. The early transition effect is the result of an increase in exit to jobs mediated by the PES. Entry into jobs found through other channels are initially reduced due to search effort substitution, but then increase and level out at zero. The reversal of the initial search effort substitution provides evidence for a higher monitoring intensity among vacancy receivers. As monitoring is also likely to affect the willingness to apply and accept vacancies by the PES, our findings suggest that monitoring improves the returns to early information and limits the costs of crowding out of search effort.

Regarding subsequent ALMP entry rates, we do not find evidence that early receipt of vacancies changes the rate of ALMP entry in the overall sample. Subsample analyses by gender and local labor market conditions show however that men and unemployed living in areas of high unemployment are less likely to enter 
ALMP in the medium-run if unemployment continues. As the PES units in regions of high unemployment are more likely to be budget constraint, it seems reasonable to relate the reduction in ALMP entry to a more focussed targeting of ALMP towards individuals for whom no vacancies are available. The reason for the gender differences are not as easily linked to budgetary concerns. They may hence be related to a stronger dislike for ALMP among men (see, e.g., Pedersen et al., 2012). Assuming that the ALMP participation is the outcome of a negotiation between caseworker and unemployment, caseworker be more lenient towards men, if it a direct labor market entry via vacancies seems possible. We do not find that that reduction in ALMP mediates the employment transitions. While further research is needed to understand the mechanism of ALMP reduction, we suggest that early information may entail a double dividend by improving the cost-effectiveness of the activation even in the absence of direct employment effects.

In terms of employment quality we find that vacancy receivers are more likely to accept jobs in temporary work agencies and work slightly fewer hours. As temporary work agency vacancies are over-represented at the PES, the quality effect is likely to be a direct results of selective vacancy registration and monitoring.

The paper is organized as follows. Section 2 outlines the job search theoretic predictions of the effects of vacancy information and reviews the findings of the earlier related literature. Section 3 sketches the institutional specification of the German activation practice. Section 4 introduces the data and defines the treatment and outcome variables of interest. Section 5 outlines the empirical strategy, and Section 6 presents the empirical results. Finally, Section 7 concludes.

\section{Theoretical Predictions}

Theoretical models of job search provide a helpful starting point in assessing the mechanisms by which vacancy information affects the employment transition and the quality of accepted employment. In the following, we briefly and verbally outline their basic intuition. Assuming that search is costly in terms of time and money, job search models posit that unemployed maximize the value of search by allocating search effort to information channels that are most productive. For a given level of search effort, the value of current unemployment is assessed based on the costs and the expected returns to search. This value serves as reference level (reservation wage) for any arriving job offer: job offers paying a higher discounted wage than the 
current value of search are accepted. Considering search effort and reservation wages as endogenous, predictions on the effects of vacancy information on employment transitions and quality of accepted employment, with or without monitoring, can be derived.

Employment Transitions For simplicity, we assume that unemployed use two stylized search channels, a PES channel and a non-PES channel capturing all other commonly used search channels, e.g., the internet, friends and family, newspaper ads, unsolicited applications, etc. The provision of vacancy information from the PES represents an exogenous increase in the productivity of job search via the PES, which is expected to increase the probability to enter employment via jobs found through the PES. It is sensible to assume that non-PES channels are substitutes to the PES search, so that their productivity is not affected by this. However, unemployed are expected to respond to the relative productivity change by redistributing search effort away from non-PES channels towards the PES channel. Search effort substitution reduces the transition through non-PES channels, dampening or even offsetting the positive effects of PES vacancy information on the overall transition rate (see, Holzer, 1988; Fougère et al., 2009, for more details).

Additional Monitoring Job search monitoring reduces the value of unemployment by forcing unemployed to invest more search effort by threats of benefit sanctions (see, e.g., Abbring, van den Berg, and van Ours, 2005). Higher search effort is expected to increase the exit rate from unemployment. Due to search channel substitution, the effectiveness of monitoring depends on the ability of caseworkers to monitor search effort in all channels. If search effort is comprehensively monitored, simultaneous monitoring is expected to reduce the possibility of search channel substitution. If vacancy receivers are hence simultaneously subject to more intensive monitoring, their exit rate in both non-PES and PES channels is expected to increase. Imperfect monitoring in contrast may aggravate the channels substitution. For example, if only the effort in the PES channels is monitored, unemployed may decrease their non-PES search effort to an even larger extent than in the nonmonitoring case, as they are now forced to invest a sub-optimally high effort in the PES search channels (see, van den Berg and van der Klaauw, 2006, for more details). If the returns to PES search are lower than that from non-PES search, the overall employment transition may be reduced. 
Note, that a simultaneous increase in anticipated ALMP entry may have a similar effect as comprehensive monitoring. In particular, if unemployed expect low returns to ALMP, they may invest more search effort in all channels to avoid participation. The ex-ante employment effect of announced ALMP participation was documented by, e.g., Black, Smith, Berger, and Noel (2003); Graversen and van Ours (2008). Van den Berg, Bergemann and Caliendo (2009) show that a higher perceived probability of ALMP entry increases search effort and lowers reservation wages.

Employment Quality Theoretical predictions of the effects of vacancy information on employment quality are ambiguous. By increasing the returns to search, the reservation wage is expected to go up, resulting in a higher selectivity and a higher quality of accepted employment. ${ }^{2}$ At the same time, if the average quality of jobs registered at the PES is lower than the vacancies available from non-PES channel, unemployed receiving very few job offers from non-PES channels may be willing to accept jobs of lower quality rather than accepting no jobs. Monitoring and sanctions are expected to reduce the reservation wage and may thus promote the take-up of lower quality jobs in either channel. Previous evidence on the negative quality effects of monitoring is given by e.g., Arni, Lalive, and Van Ours (2012).

\section{[Insert Table 1 about here.]}

Overall, it can be seen that the job search theoretical predictions on channelspecific employment entry depend on whether vacancy information is accompanied by monitoring or not. A simplified summary of the outlined channel-specific effects is given in Table 1. These differential predictions are used to interpret the findings of the channel-specific exit rates.

\section{Institutional Setting}

The German system of passive and active unemployment support is strongly centralized providing all services from the PES. The PES operates through local entities that enjoy some degree of freedom in adapting their services to local labor market conditions. They are however bound by the same institutional regulations, and

\footnotetext{
${ }^{2}$ Note, that the increased selectivity may also slow down the exit rate, as fewer job offers are considered acceptable. As shown by van den Berg (1994), the positive effect of the higher search productivity is expected to outweigh these countervailing effects, so that we do not discuss them further here.
} 
adhere to similar practical activation guidelines. In our study we focus on the regulations pertaining to unemployed eligible to unemployment benefit (UB) receipt. ${ }^{3}$ The statutory framework for the UB entitlements, the rights and duties of the unemployed and the caseworker are outlined in the Social Code III (SGB III), and are complemented by practical directives.

Unemployment Benefits During the period of observation, unemployed individuals are entitled to UB if they were employed subject to social security contributions for at least twelve months during the 24 months preceding unemployment entry. The level of UB amounts to $60 \%$ ( $67 \%$ for unemployed with children) of the average gross wage earned during the previous twelve months. The duration of UB entitlement depends on the duration of employment during the reference period. For individuals below the age of 50, the maximal duration of UB payment is twelve months, older individuals are entitled to longer benefit receipt. An additional prerequisite for UB receipt is the willingness to work, which is defined as an active search for employment, the willingness to accept reasonable job offers ${ }^{4}$, and the availability for participation in ALMP. If the behavior of unemployed does not reflect the willingness to work, the UB payments can be temporarily suspended. The duration of the sanction lies between two to three weeks. During the period of observation, the overall propensity to be sanctioned due to non-compliance is quite low at $1 \%$. The incidence of sanctioning during unemployment is found to vary systematically across labor markets and PES units (see, Müller and Oschmiansky, 2006; Müller, 2007).

Early vacancy information At the local PES, unemployed are assigned to a caseworker who accompanies and monitors the job search process and decides about the use of activation instruments. Caseworkers are encouraged to adapt the timing and type of activation tools to the needs of the individual. To get an idea about common principles governing the regular activation process we rely on assessments of the caseworker activities in practice by Hielscher and Ochs (2009), Schütz et al. (2011a), and Boockmann, Osiander, Stops, and Verbeek (2013).

\footnotetext{
${ }^{3}$ Unemployed not entitled to UB receipt can receive means-tested unemployment assistance, and are subject to different regulations. We do not address these regulations here.

${ }^{4}$ Jobs that pay less than $80 \%$ of the last wage, require more than 2.5 hours commuting time or the change of occupation are not considered acceptable. Short-term employment and employment requiring transitory separation from the family are also not considered reasonable. Over the course of unemployment, the reasonableness criteria are tightened: after three and six months in unemployment, larger wage cuts and longer commuting times are considered reasonable.
} 
All UB claimants are required to attend an immediate initial meeting with the caseworker, the main objective of which is to conduct a detailed profiling of the unemployed and to discuss reintegration steps. The discussion of specific vacancies and the overall labor market situation are a particularly important element of the early meetings (see, Hielscher and Ochs, 2009; Schütz et al., 2011a). The referral of vacancies is based on a computerized matching between characteristics of the unemployed and vacancies registered at the PES. Time and effort spent on the personal assessment and vacancy search are at the discretion of the caseworker.

Vacancies registered at the PES are commonly "open" in that all unemployed may apply to them, and they are publicly accessible via an online information system. However, they only represent a subset of all vacancies in the labor market. The average share of vacancies registered at the PES ranged between $30 \%$ and $50 \%$ on average between 2007 and 2008 (IAB, 2008). Evidence on the selectivity and the quality of registrations for specific occupations and qualification levels suggests that the coverage rate is lower for higher qualified jobs (Christensen, 2003; Koppel, 2008). Furthermore, vacancies from the temporary work sector are highly over-represented compared to their importance in the labor market. ${ }^{5}$

Differences in caseworker resources and vacancy registration rates across occupations and PES units may introduce variation in early information provision that is independent of the overall state of the labor market. As outlined by Hofmann et al. (2012) and Hainmüller et al. (2015) the time spent per unemployed is a function of the caseload per caseworker and hence the staffing at the local PES. Furthermore, the registration rate of vacancies may depend on the perceived effectiveness of registering vacancies at the PES by firms. Negative previous experiences with posting vacancies at the local PES may reduce the use of PES for vacancy postings (Müller, Rebien, and Stops, 2011). Self-assessed use of working time among German caseworkers suggest that they spend little time with the acquisition of vacancies (Boockmann et al., 2013).

Monitoring Both the timing of the intensity of monitoring in general are at the discretion of the caseworker. While it is common that the application to vacancies is monitored, both monitored and non-monitored early vacancies are observed in

\footnotetext{
${ }^{5}$ The high incidence of temporary work vacancy posting is likely to be a remnant of regulations in place between 2003 and 2006 that required that every PES had to install a Temporary Work Agency (TWA) who would then be in charge of training the unemployed or lease them in fixed-term employment.
} 
practice (Schütz et al., 2011). Also, the intensity of monitoring may be staggered: after an initial 'grace period' with only little monitoring, the monitoring intensity tends to be increased after some point in time (Hielscher and Ochs, 2009). Similarly, the incidence of sanctions over the unemployment spell is found to be lower during the first three months than during later months (Müller, 2007).

ALMP The initial profiling of the unemployed also serves to identify structural hurdles to labor market entry, and the benefit of participation in training or qualification schemes. The allocation to ALMP programs is done either by the caseworker, or via a placement voucher that allows unemployed to choose a private training or placement provider. While unemployed are entitled to receive a voucher after six weeks in unemployment, it is again at discretion of the caseworker to decide whether or not to grant the voucher. According to caseworker interviews, specific needs or requests of the unemployed and program availability are the most important decision criteria for the choice of specific activation instruments (Boockmann et al., 2013).

\section{Data and Descriptive Statistics}

To assess the effectiveness of early vacancy information, we use a representative survey of unemployment entrants in Germany, the IZA Evaluation Dataset Survey (Caliendo et al., 2011). The sampling of the survey was based on monthly unemployment entrants between June 2007 and May 2008 who were between 17 and 54 years of age and eligible to receive unemployment benefits. In a baseline interview that took place between eight to eighteen weeks after unemployment registration, respondents answered an extensive questionnaire about general socio-demographic characteristics, the previous employment history and their job search behavior, as well as non-standard questions regarding expectations, preferences and personality traits. Most relevant for our analysis are questions about activation offers by the PES capturing the receipt of vacancy information and the types of ALMP offered during early unemployment. Follow-up interviews conducted one and three years later capture the subsequent labor market biography of unemployment entrants, including timing and characteristics of employment, unemployment, and ALMP spells on a monthly level. Focussing on early vacancy receipt the employment outcomes during the first year after unemployment entry are of most interest. We thus restrict the estimation to individuals participating in the first and second survey wave. Unfortu- 
nately, the data collection was marked by significant sample attrition, resulting in a reduction of the sample by about $50 \%$ from the first to the second interview. Comparisons by age, gender and migration status do not provide evidence for selective attrition (Caliendo et al., 2011).

We restrict the empirical analysis to unemployed who stated to actively search for full-time employment, who receive or are eligible to receive UB benefitsand who are older than 25. This ensures that the unemployed are subject to the same activation regulations. Finally, we exclude observations with missing values in any of the relevant variables, resulting in a total sample size of 4,044 unemployed. Table 2 documents the sample selection procedure.

\section{[Insert Table 2 about here.]}

Due to a delay in the timing of the first interview, about $25 \%$ of unemployment entrants had already left unemployment at point of the first interview. All of the relevant questions in our analysis are identical for both currently employed and unemployed.

\subsection{Treatment Measure}

Whether or not vacancy information was received during early unemployment is derived from a multiple-response question on the type of activation instruments offered by the PES since unemployment entry. The question was asked during the first interview and thus captures vacancies received before on average twelve weeks after unemployment entry. ${ }^{6}$ Vacancy information for fulltime jobs, part-time jobs, and jobs in temporary work agencies (TWA) are distinguished. We consider individuals receiving any of these vacancies as treated, resulting in a $40 \%$ treatment share. Among the treated, $92 \%$ have received fulltime vacancy offers that are expected to be the most relevant for this sample. Sensitivity analyses show that the effect estimates do not change when considering only fulltime vacancy information as treatment. ${ }^{7}$

The use of a single measurement of vacancy receipt as treatment indicator implicitly assumes that the assignment to early vacancies happens at a fixed point in time. At point of the interview, all unemployed had attended at least one meeting

\footnotetext{
${ }^{6}$ This captures the extensive margin. The number of vacancies received is not known.

${ }^{7}$ The results are available upon request.
} 
with their caseworker. ${ }^{8}$ Based on the observation that vacancies are a main element of discussion during early meetings, this static treatment indicator should capture predominantly 'early meeting vacancies'. In practice, the provision of vacancy information may not be limited to early meetings, so that unemployed may also receive their first vacancy later. This is expected to attenuate our effect estimates towards zero. Furthermore, dynamic assignment to treatment may change the treatment selection over time, as unemployment leaving unemployment quickly are less likely to receive vacancy information. For individuals still unemployed at point of the interview similar dynamics can be ensured until the point of treatment measurement by controlling for the timing of the interview. However, if non-receivers who exited before the interview did not receive vacancy information because of their early unemployment exit our estimates will be downward biased.

[Insert Table 3 about here.]

To get an idea about early dynamics in vacancy receipt, we can use variation in the interview timing that was predominantly driven by administrative processes and scheduling issues (Caliendo et al., 2011). As different interview times capture similar unemployed at different unemployment durations, an increasing share of treated over time is indicative of a highly dynamic treatment assignment. Table 3 shows that the treatment probability is fairly stable at $40 \%$ over the interview period with a slight increase for interviews later than 15 weeks. As we are considering the extensive margin of vacancy receipt, this distribution translates in an early peak in the hazard to receive vacancy information and a positive but much diminished hazard during later unemployment. This hence suggests that our static vacancy measure indeed captures a similar early treatment for the large part of our sample.

The dynamics indicated by the higher treatment share during later interviews suggest that negative selection into treatment may downward bias treatment effect estimates for later interviews. To assess the relevance of this, we conduct a subsample analysis in Section 6.4, restricting the sample to individuals interviewed before twelve weeks in unemployment. This lowers the share of individuals having exited unemployment, and thus limits the scope for negative selection into treatment.

As vacancy receivers may be exposed to additional monitoring, a varying monitoring intensity among the non-treated over time also need to be taken into account.

\footnotetext{
${ }^{8}$ Individuals were asked about the number of contacts with the caseworker. Only $2 \%$ stated to not have had any.
} 
If the monitoring intensity increases over time for all unemployed (see Section 3), the effects of the monitoring component of early vacancy information may be gradually reduced. Unfortunately we do not observe timing or intensity of monitoring.

\subsection{Outcome Measures}

Employment Transitions Our main outcome of interest is the transition rate into employment subject to social security contributions within the first 13 months following unemployment entry. Exits from unemployment later than 13 months are assumed to be censored at random. ${ }^{9}$ Next to considering the effect on the overall transition rate, information on the successful search channel allows us to distinguish between exits made with the help of the PES and exits through non-PES channels, comprising, e.g., jobs found through the internet, newspapers ads, unsolicited applications, etc. Search via the PES online information system or search via private agencies using a voucher may be complementary to vacancy receipt, so that we attribute jobs found through these channels to the PES. Note, that these only account for $4 \%$ of exits. The left panel in Figure 1 presents the unconditional survival rates for treated and controls. After 13 months, treated are 8\%-points more likely to have exited unemployment. The source of the gap seem to be differences in PES entry rates.

\section{[Insert Figure 1 about here.]}

ALMP Transitions To asses whether vacancy information affects the entry rate in ALMP we consider joint entry rates into job creation schemes and training programs. ${ }^{10}$ The right panel of Figure 1 depicts the entry rate in ALMP conditional on remaining unemployed. Unconditionally, no significant gap between treated and controls emerges. During the 13 months, about $20 \%$ of unemployed entered ALMP.

By our inability to observe the exact timing of vacancy receipt, it could arise that vacancy receipt occurs while individuals are locked-in in ALMP. As direct labor market placements are likely to be preferred by the PES, participation in ALMP is most likely to occur subsequent to vacancy referral. To assess the sensitivity of our

\footnotetext{
${ }^{9}$ The timing of the second interview was conducted independent from labor market status.

${ }^{10}$ This comprises participation in publicly sponsored general schooling or training, retraining, short-term training, and job search programs. Employer subsidies were not recorded consistently over the two interview periods and are thus not included.
} 
results to early ALMP entry we omitted unemployed who entered ALMP before the first interview. This did not change the effect estimates. ${ }^{11}$

Employment Characteristics For unemployed entering regular employment during the period of observation, we assess the effect of vacancy information on employment quality. For this we consider the hourly wage levels, the weekly number of hours worked, whether the accepted jobs were temporary, i.e., limited in their duration to less than one year, and whether the job was at a temporary work agency (TWA). In the overall sample, the average hourly wage is 8.30 Euros, with 41 average weekly hours worked. About $14 \%$ of accepted jobs are in a TWA and $40 \%$ are temporary. Table 4 presents unconditional averages by treatment indicator. Significant differences emerge regarding the successful channel, with $21 \%$ of treated accepting a job via the PES, compared to only $10 \%$ of controls. Regarding the employment quality, only TWA employment differs significantly, with $12 \%$ of non-treated, compared to $16 \%$ of the treated having accepted a job in a TWA.

[Insert Table 4 about here.]

\subsection{Descriptives of Pre-treatment Differences}

Table 5 presents selected descriptives of socio-demographic characteristics, employment history and job search behavior of treated and controls. Overall, receivers of vacancy information are slightly younger, more likely to be male and less likely to be married. They also are more likely to have a vocational degree rather than no degree or a tertiary university degree. Furthermore, vacancy receivers tend to have a slightly better labor market history, as reflected by a lower number of previous unemployment spells and a higher level of UB, they live in areas with better local labor market conditions (i.e, lower unemployment rate, higher vacancy rate), and are more active in sending out applications. In summary, this suggests that receivers of vacancy information are positively selected with respect to their labor market characteristics.

[Insert Table 5 about here.]

Cross-tabulations of vacancy information receipt with offers of other activation instruments show that receivers of vacancy information also differ with respect to

\footnotetext{
${ }^{11}$ The results are available upon request.
} 
being offered alternative types of activation. Grouping the offers by whether they are targeted at a direct labor market entry or an intermediate entry via more intensive ALMP, it can be seen that vacancy receivers are subject to more intensive activation in both domains. For example, vacancy receivers are significantly more likely to receive placement vouchers (11\% vs. $9 \%$ ), to be offered participation in work-training (18\% vs. $11 \%$ ) or to be offered training courses for the improvement of employability (12\% vs. $9 \%$ ). This positive relation between vacancy information receipt and being offered high intensity measures suggests that simultaneous differences in the use of activation instruments needs to be accounted for.

\section{Econometric Analysis}

To formalize the evaluation problem, let $D$ denote a binary treatment indicator, with $D=1$ for early vacancy receivers and $D=0$ for non-receivers. We are interested in estimating the effect of treatment on an outcome $Y$. Using the potential outcome framework notation developed by Roy (1951) and Rubin (1974), each individual is characterized by two potential outcomes, one in the treatment state $Y(1)$ and one in the non-treatment state $Y(0)$. Our parameter of interest is the average treatment effect (ATE) which is defined as $\tau=E(Y(1))-E(Y(0))$. In observational studies, the difference between average observable outcomes conditional on treatment status, $E(Y(1) \mid D=1)-E(Y(0) \mid D=0)$ does not identify the ATE as non-random selection into treatment implies that $E(Y(0) \mid D=1) \neq E(Y(1) \mid D=1)$ and $E(Y(1) \mid D=0) \neq E(Y(0) \mid D=0)$. A common strategy to address this identification problem is to assume that the specific factors influencing both the treatment decision and the outcomes of interest are known. Provided that they are also observable, conditioning on these confounders in the empirical analysis will eliminate systematic differences between the observable and the potential outcomes. Let $X$ denote the factors affecting treatment and the outcome of interest. The conditional independence assumption (CIA) posits that

$$
D \Perp Y(0), Y(1) \mid X,
$$

implying that when controlling for $X$, the potential outcomes are independent of the treatments status. Assuming further that the distribution of $X$ has a joint support in the treatment and the control group, i.e.,

$$
0<P(D=1 \mid X)<1
$$


the ATE is estimated by $\hat{\tau}=E(Y(1) \mid D=1, X)-E(Y(0) \mid D=0, X)=E(Y \mid D=$ $1, X)-E(Y \mid D=0, X)$. While the common support condition can be tested or visually assessed, the validity of the CIA assumption depends on the availability of sufficiently informative data and needs to be assessed on a case-by-case basis for the respective evaluation and data setting. We discuss the validity of the CIA assumption in detail in Section 5.2.

A further assumption relevant in the assessment of treatment effects, is the assumption of no interaction or spill-over effects, i.e., the "stable unit treatment assumption" (SUTVA). This precludes that the provision of vacancy information creates a direct disadvantage for non-receivers to get the job. As suggested by the institutional setting, the variation in vacancy information provision may be attributable to differences in registrations of vacancies across professional groups, rather than across workers directly competing for jobs. Furthermore, as we are considering open vacancies, the information is technically available to everyone, implying that the competition increase due to informing one additional unemployed is expected to be small. We hence argue that the role of displacement is probably small, however it cannot be ruled out and may indeed upward bias our estimates.

\subsection{Empirical Strategy}

To estimate the effect of receiving vacancy information on the exit rate from unemployment, we adopt a flexible semi-parametric estimation approach using propensity score matching (Rosenbaum and Rubin, 1983). Previous applications of matching estimators with duration outcomes are found in context of dynamic treatment selection problems, where they are considered as alternative to parametric mixed-proportional hazard models (see, e.g., Fredriksson and Johansson, 2008; Crepon, Jolivet, Ferracci, and van den Berg, 2009; Kastoryano and van der Klaauw, 2011; Vikström, 2014). Parametric duration models rely on the proportionality of hazards assumption, and account for potentially unobserved confounders by specifying an unobserved heterogeneity distribution (see, for details, van den Berg, 2001). Relative to these models, matching estimators use less restrictive modelling assumptions, but need to adopt the conditional independence assumption. As our data are very informative with respect to the problem-specific confounding factors, we consider the increased flexibility of the semi-parametric approach as more relevant. Based on Vikström (2015), the static matching estimator can be straightforwardly extended to allow dynamic 
treatments, which allows us to disentangle the direct transition effects of early vacancy information and the transition effects resulting from differential subsequent ALMP entry.

A caveat of the matching estimates for effects on duration outcomes, is that only the instantaneous effect on exit rates is point-identified, whereas the subsequent effects are a mix of treatment effect and relative changes in composition of treatment and control groups over time (see, for a detailed discussion Vikström, Ridder, and Weidner, 2015). If the initial treatment interacts with specific characteristics of the unemployed, treated with these characteristics exit differently than controls, resulting in an unequal comparison of hazard rates in any subsequent periods. As our sample of unemployed is rather homogenous on the outset, the changes in composition are not expected to be very strong. However as more individuals exit over time, these dynamics need to be kept in mind when interpreting the medium to long run effects. Crepon et al. (2009) suggest that blocking rather than matching on the propensity score may reduce the dynamic selection as individuals with initially similar propensity scores remain in the same block throughout. As sensitivity analysis we hence apply propensity score blocking in Section 6.4.

Static Treatment Estimation To estimate the effect of (static) early vacancy receipt the Rosenbaum and Rubin (1983) matching estimator is applied. Based on estimates of the propensity scores $\hat{p}^{d}(X)=\operatorname{Pr}(D=d \mid X), d=0,1$, the balancing weights $w^{d}$ are calculated as a function of the propensity score distance, aligning the distribution of the respective other group to the distribution of characteristics in $d$ (see, e.g., Smith and Todd, 2005). Let $N_{d}, d=0,1$ denote the number of treated and controls, with $\pi_{d}$ representing the respective share in the sample. The ATE is given by

$$
\hat{\tau}=\pi_{1}\left[\frac{1}{N_{1}} \sum_{i: D=1}\left[Y_{1 i}-\sum_{j: D=0} w_{i, j}^{0} Y_{0 j}\right]\right]+\left(1-\pi_{1}\right)\left[\frac{1}{N_{0}} \sum_{j: D=0}\left[\sum_{i: D=1} w_{i, j}^{1} Y_{1 i}-Y_{0 j}\right]\right] .
$$

The effect of vacancy information on employment transitions after $t$ periods in unemployment $\hat{\tau}^{e}(t)$, is obtained by replacing $Y_{i}$ by the non-parametric Kaplan-Meier (Kaplan and Meier, 1958) survival function estimate $\hat{S}_{i}(t)$. The same is done to estimate the effects on the ALMP transition $\hat{\tau}^{a}(t)$, whereby all unemployed who have not left unemployment and not entered ALMP previously are considered at risk. To obtain the effect on channel-specific exit rates $\hat{\tau}_{c}^{e}(t)$, only jobs found through channel $c$ are considered, assuming other exits as censored. As individuals are only at risk 
provided that they survive until $t$, Kaplan-Meier survival functions inflate the true exit rates in a competing risk framework (Gaynor et al., 1993). We thus estimate the cumulative incidence function, defined as the product of the channel-specific hazard rates $h_{c}(t)$ and the overall survival rates: $\hat{F}_{i c}(t)=\sum_{i: t_{i}<t} \hat{h}_{i c}(t) \cdot \hat{S}_{i}(t-1)$. Finally, the estimation of treatment effects on employment quality of the first accepted job $\hat{\tau}^{q}$ is obtained by plugging in the outlined job characteristics in (3).

Dynamic Treatment Estimation The PES activation may also involve participation in intensive ALMP programs which may be allocated differentially depending on whether the unemployed previously received vacancies. A differential participation in ALMP subsequent to (potential) vacancy receipt may thus drive part of the effects in the entry rates into employment. ${ }^{12}$ To gain an understanding about the importance of differential ALMP entry in the treatment effect estimates, hypothetical counterfactual transition rates can be constructed for a scenario in which subsequent ALMP participation is the same for treated and controls. One interesting treatment sequence highlighting the role of subsequent ALMP entry is the scenario in which no one participates in ALMP during unemployment.

As we observe the timing of entry into ALMP, we can estimate the transition rates in this hypothetical scenario by censoring unemployment survivors once they enter ALMP. Vikström (2015) proposes a reweighing scheme to account for this selective censoring, showing that under the assumption of sequential conditional independence between ALMP entry and unemployment exit rates among survivors in a given period $t$, the hypothetical counterfactual survival rates in both treatment arms can be consistently estimated. Let $T_{d^{*}}$ and $T_{u}$ denote time until entry into ALMP and the duration of unemployment, respectively, whereby $D^{*}(t)=\mathbf{I}\left\{T_{d^{*}}=t\right\}$ represents an indicator of ALMP entry at $t$. The sequential CIA assumption for vacancy receivers and non-receivers is hence given by

$$
D^{*}(t) \Perp S^{d}(t) \mid X, T_{d^{*}} \geq t, T_{u} \geq t, D=d, \text { with } d=0,1 .
$$

Further we assume that conditional on the same treatment path up to $t$ and conditional on $X$, the potential outcomes in $t$ do not depend on future entry into ALMP (the no anticipation assumption, see Abbring and van den Berg (2003)), and that the common support condition holds in each period. The treatment effect estimate

\footnotetext{
${ }^{12}$ In the following, the labels 'treated' and 'controls' refer to vacancy receipt only.
} 
for the outlined treatment sequence is hence given by

$$
\tau^{*}(t)=\prod_{t=1}^{T}\left[1-\frac{w^{1} h_{u}(t) \mathbf{I}\left\{T_{d^{*}}>t\right\} \mathbf{I}\{D=1\}}{\prod_{t=1}^{T}\left(1-\hat{p}_{t}^{1}(X)\right)}\right]-\prod_{t=1}^{T}\left[1-\frac{w^{0} h_{u}(t) \mathbf{I}\left\{T_{d^{*}}>t\right\} \mathbf{I}\{D=0\}}{\prod_{t=1}^{T}\left(1-\hat{p}_{t}^{0}(X)\right)}\right]
$$

with $\hat{p}_{t}^{d}(X)=\operatorname{Pr}\left(T_{d^{*}}=t \mid X, T_{u} \geq t, T_{d^{*}} \geq t, D=d\right)$ representing estimates of the conditional probability to enter ALMP in period $t$, provided that the unemployed have not entered treatment before.

\subsection{Conditional Independence Assumptions}

The validity of the identifying assumptions (1) and (4) cannot be tested and need to be discussed carefully. The descriptive analysis suggests that vacancy receipt is positively correlated with the availability of jobs in the overall labor market and the activation efforts of the caseworker, both of which may have an own positive effect the transition rate into employment. To address the first source of confounding, we condition on an extensive set of individual and local labor market characteristics, aiming to capture differences in the overall search productivity. Individual characteristics include demographic indicators, educational attainment, health indicators, personality traits (see Goldberg, 1993, for the "Five Factor" model), level of UB receipt and indicators of the past labor market history, including information on number of previous unemployment spells, incidence of long-term unemployment, information on the last employment spell and the reason for entering unemployment. The relevance of the previous labor market history for capturing unobserved characteristics was highlighted by Lechner and Wunsch (2013) and Caliendo, Mahlstedt, and Mitnik (2014). Further, we condition on home ownership, availability of internet access at home and indicators of the social network to capture differences in the availability and productivity of other search channels. Systematic regional and seasonal variation in local labor market conditions are accounted for by indicators of the unemployment rate and the share of registered long-term unemployed.

To address confounding due to simultaneous exposure to other activation measures, we need to capture systematic differences in the propensity to enter other ALMP, or the expectation to enter ALMP, as this is found to shape the ex-ante behavior of the unemployed thus affecting exit rates directly. To approximate these differences we include information on the types of ALMP offered by the caseworker. ${ }^{13}$

\footnotetext{
${ }^{13}$ Van den Berg et al. (2009) use the subjective ALMP participation probability as indicator of
} 
Note that this may capture both caseworker or PES specific activation effects and unobserved characteristics of the unemployed. Regional indicators for the share of unemployed in training ALMP, the occurrence of sanctions, and the coverage rate of vacancies over all sectors, and for the TWA sector separately are also controlled for, all of them measured at point of unemployment entry.

\subsection{Implementation of the Matching Estimator}

To implement propensity score matching we proceed by estimating the propensity score including the outlined relevant characteristics $X,{ }^{14}$ using a probit regression model. To rule out that outliers in the predicted probabilities receive too much weight in the matching analysis, we impose a common support condition excluding treated observations with propensity score values (smaller) larger than the (minimal) maximal value of the controls - and vice versa for controls (Dehejia and Wahba, 2002). The elimination of the extreme values results in the deletion of only very few observations and is hence not expected to affect the representativeness of our estimation sample.

Matching is conducted using kernel matching with an Epanechnikov kernel, which has been shown to produce reliable estimates in a number of data settings $(\mathrm{Hu}-$ ber, Lechner, and Wunsch, 2013). The bandwidth is selected to minimize the mean standardized bias (MSB) over all confounders (see, e.g., Caliendo and Kopeinig, 2008). Adopting the approach proposed by Huber, Lechner, and Steinmayr (2015), a grid search is conducted using multiples of the largest distance in propensity scores obtained from pair-matching with replacement, ${ }^{15}$ ultimately selecting the bandwidth that minimizes the MSB.

\section{[Insert Table 6 about here.]}

The resulting balancing quality in terms of the MSB and the $t$-test are presented in Table 6 for the total sample and the employment sample, respectively. As $p$-values of standard statistical tests are not very reliable in the matched sample (Lee, 2011),

interest, which is only available for individuals still unemployed at the first interview. Regressing this indicator on vacancy receipt and a number of labor market characteristics, the coefficient on vacancy receipt becomes insignificant once controlling for ALMP offers, suggesting that ALMP offers represent a similarly good approximation for differences in the anticipated ALMP participation.

${ }^{14}$ Additionally we include information on month of entry into unemployment, and elapsed unemployment duration at point of the interview. For the estimation of propensity score in the employment sample, we additionally include an indicator of the timing of the transition

${ }^{15}$ The multiples chosen were $(0.25,0.5,1,2,2.5,3,4,5)$. 
it is advised to maximize the minimum $p$-values over all variables. It can be seen that matching results in a substantial reduction in imbalance; none of the characteristics exhibits a significant difference in characteristics by conventional significance levels and the average standardized bias is always well below $5 \%$ which is usually considered a sufficient level of balance (Caliendo and Kopeinig, 2008).

For the dynamic matching estimator, we estimate the probability to enter ALMP for survivors in the respective treatment groups in each period separately. We use a more parsimonious specification than outlined previously including only indicators with the highest predictive power in the overall specification, including information on ALMP offers. As inverse probability weights may be very sensitive to extreme weights, we further apply careful trimming, setting observations whose share in the sum of all weights in the treatment (control) group is greater than $5 \%$ in all periods to zero, as suggested by Vikström (2015). Sensitivity analyses suggest that larger trimming values do not change the results. Finally, inference is based on bootstrapped standard errors using 199 bootstrap replications. Based on random draws from the estimation samples, the bootstrap procedure replicates the whole matching procedure, including the estimation of the propensity score. All estimations are conducted separately for joint sample and the respective labor market groups.

\section{Results}

This Section presents the effect estimates of early vacancy information on employment transition rates, employment quality and ALMP transition rates. The effect estimates are obtained by the propensity score matching analyses outlined in Section 5 , balancing the relevant pre-treatment characteristics across treatment groups. In particular, by conditioning on labor market characteristics from before unemployment entry as well as early ALMP offers, the expected employment and activation path is expected to be similar ex-ante, implying that any subsequent differences are the result of vacancy receipt.

\subsection{Effects on Employment and ALMP Transitions}

Employment Transitions The first row of Figure 2 depicts the effect estimates for overall and channel-specific transition rates into employment. All effects are presented for the first 13 months in unemployment. As we focus on early vacancies, the 
effects on employment exits are expected to be strongest shortly after unemployment entry. Changes in the monitoring intensity or ALMP participation rate later on may change the effects on the medium-run.

It can be seen that early vacancy information has a strong positive impact on overall employment entry rates during the second and fourth month in unemployment. This early boost in overall exit rates results in a 7\%-point gap between treated and controls. Before and after, the overall employment hazard between treated and controls do not differ; the early vacancy effect hence translates in a stable and longrun employment effect. Splitting up exits by jobs found via the PES or non-PES channels, it can be seen that the early employment effect is mainly attributable to an increase in the exit rate through the PES channel between the first and third month in unemployment, resulting in a positive effect of 6\%-points after three months. Afterwards, the PES hazard continues to increase slightly, resulting in an total 8\%point gap after 13 months. The early effects on non-PES hazard rates in contrast are initially negative, then positive, and finally level out at zero after four months.

[Insert Figure 2 about here.]

The size of the initial decrease in non-PES hazard rates is at $-3.5 \%$-points at two months, thereby cancelling out the simultaneous increase in the PES hazard rates. This countervailing effects supports the search-theoretic hypothesis of search channel substitution: receivers of vacancy information reduce search effort in other channels, thus lowering the chances of job offers through these channels (see, Fougère et al., 2009, for similar findings). As the crowding out of non-PES search lowers the benefits of additional information, and thus the effectiveness of vacancy information policies, simultaneous monitoring may ensure that individuals continue to search via non-PES channels. Recall, that in the absence of such monitoring policies, the hazard of non-PES exit rates is expected to be either zero or negative. The sign reversal in early non-PES hazard rates hence suggests that non-PES exit rates are subject to a higher early monitoring intensity that counteracts the initial search channels substitution. Note, that no changes are observed for PES hazard rates, so that this effect does not seem to be the result of a reversal in the intensity of later vacancy receipt amongst treated and controls. As we control for initial differences in ALMP offers we also ensure that this is not driven by a higher threat of subsequent ALMP entry. Overall this suggests that the combination of vacancy information and monitoring reduces the unintended substitution effects of additional information. 
The leveling out of the monitoring effect after month four is likely to be explained by the increasing monitoring intensity also for controls, attenuating the monitoring component of vacancy information. Clearly, monitoring is also likely to affect the entry rate into PES jobs, so that the high PES entry rate is likely to be a combination of both.

ALMP Transitions Figure 5 depicts the effects on the transition rate into ALMP conditional on remaining unemployed. It can be seen that receivers of vacancy information are similarly likely as controls to enter ALMP provided that they remain unemployed. Early vacancy information hence does not seem to alter the intensity of ALMP participation. However, even in the absence of quantity effects, quality effects could affect the benefit from ALMP participation.

[Insert Figure 5 about here.]

Censored Employment Transitions The second row of Figure 2 presents the effects of employment transitions when censoring ALMP entries as outlined in Section 5. It can be seen that the effects on overall employment transitions are somewhat lower and that these changes are driven by a reduction in the effect estimates for the non-PES channel. In particular, the censored effects for non-PES channels are slightly more negative starting with month five, suggesting that ALMP participation may improve the medium-run returns to non-PES search. In the absence of any quantitative differences in ALMP entry, this could be driven by higher quality ALMP entry improving the productivity of non-PES search. Due to the increased variability of the censored effect estimates we cannot draw statistically reliable conclusions, however. In particular, the censored and non-censored results are not significantly different from each other, and the qualitative results of both estimates do not differ.

\subsection{Employment Quality}

As early vacancies predominantly affect PES channels exits, the effects on employment quality are expected to be predominantly attributable to quality difference between vacancies registered at the PES and those at other information channels. As we also find evidence for a higher monitoring intensity, the take-up of worse quality employment may be reinforced by the monitoring. Findings of a deterioration 
in employment quality are thus most likely a combination of vacancies quality and monitoring intensity.

[Insert Table 8 about here.]

The second column of Table 8 presents the effect of vacancy information on the quality of jobs accepted during the period of observation. We find that vacancy receivers are $3 \%$-points or $25 \%$ more likely to accept a job in temporary work agency, and that their weekly hours worked are reduced by about $2 \%$ or about one hour. The size of the latter effect hence seems economically negligible. No significant effects are found on the acceptance of short-term jobs or hourly wages earned.

The overall effects on employment quality are thus somewhat inconclusive, as the previous evidence on TWA employment is mixed. For unemployed with otherwise few outside options, or under very good economic conditions, TWA jobs are found to provide a stepping stone into regular employment (e.g., Jahn and Rosholm, 2014). In Germany, TWA employment does neither benefit nor harm workers in terms regular employment chances (Kvasnicka, 2009), but current TWA employment may translate into lower wages in a subsequent regular job (Jahn and Rosholm, 2014). The benefit of entering TWA employment thus needs to be weighed against by the availability of alternative job opportunities in the labor market.

\subsection{Heterogeneity}

Different labor market groups may benefit differentially from vacancy information. Fougère et al. (2009) suggest that unemployed with low returns to search experience a higher return to vacancy information, in particular as the substitution effect is expected to be lower if the productivity of non-PES search is low. To analyze potential heterogeneities in the effectiveness of vacancy information, we split the sample by gender ${ }^{16}$ and by unemployment rates $^{17}$ (below or above the median), respectively. While women are expected to be more constrained in their labor market choices, unemployed in areas of high unemployment may experience a low productivity of overall search. These subgroups are hence expected to benefit more from additional information. At the same time, the monitoring intensity may differ across the two

\footnotetext{
${ }^{16}$ In our estimation sample there are 1,764 women and 2,280 men. The treatment share are at $40 \%$ ad $45 \%$, respectively.

${ }^{17}$ The share of treated in the low unemployment regions is at $47 \%$ and $38 \%$ in the high unemployment regions.
} 
subgroups. As documented by Müller (2007), the sanction probability is lower among women compared to men, and is lower in East than in West Germany, the latter suggesting that monitoring policies may be less strict in regions with high unemployment.

\subsubsection{Gender}

Employment and ALMP Transitions Figure 3 depicts the employment transition results for men and women separately. As expected we find that the overall employment effect of vacancies is larger for women than for men. For women, the initial boost in employment transition rates results in a 10\%-point effect after 13 months, which translates into a $28 \%$ higher exit rate among treated relative to controls. For males, the effect on employment transition is at 5\%-points or $14 \%$ at the end of the observation period.

\section{[Insert Figure 3 about here.]}

The channel-specific analysis shows that the gender-differences are attributable to both PES and non-PES exits. While the effect on PES exit rates is similar early on, the effect for women continues to increase over time, while it becomes flat after the third month for men. Inspection of the underlying cumulative incidence functions shows that women in the control group are less likely to exit via the PES also later on, while non-treated men exit at a similar rate as treated after the third month. Difference in non-PES exit rates are driven by lower substitution effects among women. Both groups experience an increase in non-PES exit rates after the initial dip, however, suggesting that they are similarly exposed to intensified search monitoring. The medium-run effect on non-PES exit rates is zero for both groups.

The effects on ALMP transition rates are depicted in the upper two panels of Figure 6. While no effects are found for women, vacancy receipt has a negative effect on ALMP entry among surviving unemployed of -2.5\%-points between the third and eighth month and is marginally significant during the early months. The receipt of vacancy information thus seems to have a direct negative effect on ALMP participation for men. In line with the outlined screening hypothesis, this suggests that vacancy information signals a reduced need for ALMP. The absence of such an effect for women may be related to a stronger dislike for ALMP among men (see, e.g. Pedersen et al., 2012). If the activation path is the result of a negotiation between 
caseworker and unemployed, men may use the availability of vacancy information to negotiate their way out of ALMP.

[Insert Figure 6 about here.]

Figure 3 depicts the employment transition effects when controlling for ALMP entries. In line with the zero ALMP effects for women, we do not find the point estimates to change, although they become more noisy due to the lower number of observations used in the analysis. ${ }^{18}$ For men, the censored PES exit rates are unchanged. The censored non-PES exit rates are initially similar, but become more negative after six months. Due the increased variability of estimates this reduction is however not significantly different from zero. It hence seems that the lowered ALMP entry among men does not mediate the effects on non-PES employment transitions.

Employment Quality Gender-specific effects on employment quality are given in columns three and four of Table 8. It can be seen that the effects on TWA employment and working hours are only driven by male vacancy receivers, while no quality effects are found for women. As suggested by the significant substitution of non-PES exits, men in our sample seem to be more productive in their non-PES search. The acceptance of lower quality jobs arriving from PES vacancies thus seems to be driven by the additional monitoring rather than the need to accept any job offers. While the additional monitoring may improve the willingness to apply to vacancies, this may come at the expense of accepting lower quality jobs.

\subsubsection{Local labor market conditions}

Employment and ALMP Transitions Figure 4 depicts the effect estimates on employment transitions by local labor market conditions. Comparing the initial overall vacancy effects across labor market states, they are fairly similar at 3 to $5 \%$ points at 3 months, or $5 \%$ respectively. The comparison of channel-specific effects point to a significant interaction between labor market conditions and vacancy effectiveness. While vacancy information has a higher effect on early PES transitions if local unemployment is low ( $400 \%$ vs. $200 \%$ at month three), the effects on early non-PES exit rates are lower due to the crowding out of productive non-PES search

\footnotetext{
${ }^{18}$ Note that $17 \%$ and $23 \%$ of the sample of women and men respectively enter ALMP during the observation period.
} 
channels (-14\% vs. $-24 \%$ at the peak in month two). As the two countervailing effects cancel each other out, the overall early transition effect is similar across regions. Similarly, in both labor market areas, the initial downward trend in non-PES rates is subsequently reversed due to monitoring, resulting in a zero medium-run effect on non-PES exits.

[Insert Figure 4 about here.]

The effects on transition rates into ALMP are depicted in the lower panels of Figure 6. For unemployed living in areas of high unemployment, vacancy information does not change the ALMP participation rate. In contrast, we find a significant reduction of ALMP entry rates in regions with high unemployment up to the sixth month after unemployment entry. As before, if the availability of vacancy information is considered a positive signal of labor market chances, this may reduce the perceived need for more intensive ALMP. As the competition for ALMP may be more fierce in regions with high levels of unemployment, ALMP places may be given preferably to unemployment without any direct employment opportunities.

When accounting for subsequent the ALMP entry in the employment transition rates, we find again that the effects are largely unchanged (see Figure 4). Although the effects on non-PES exit rates are somewhat reduced in areas of high unemployment, the overall effects are not significantly different from zero.

Employment Quality The last two columns of Table 8 show that vacancy receipt only increases the take-up of TWA jobs in regions with high unemployment. The negative effect on weekly working hours seems to be reduced for both regions the point estimates are fairly similar - however, the effect is only significantly different from zero in regions with low unemployment. As before, the benefit of transiting in less attractive jobs needs to be weighed by the overall chances in the labor market of transiting into jobs. As the transition in regular employment is likely to be more difficult in regions of high unemployment, the take-up of less stable jobs, i.e., TWA employment, may nonetheless be beneficial. In contrast, the slight reduction in hours worked in regions of low unemployment, albeit economically negligible, provides some indication that monitoring may promote the take-up of worse quality employment. 


\subsection{Sensitivity Analysis}

Sensitivity 1: Blocking As outlined by Crepon et al. (2009), the use of blocking or subclassification on the propensity score (Rosenbaum and Rubin, 1984) may be more appropriate than matching methods with duration outcomes, as it limits the comparison of individuals to the subclasses defined at treatment entry. The implementation of blocking requires the choice of the number of subclasses. Cochran (1968) suggests that five subclasses are sufficient to remove $90 \%$ of imbalance in characteristics. We hence implemented block matching using five intervals. The blocking estimates on overall and channel-specific transition rates are presented in the first row of Figure 7 . The very similar effect estimates suggest that our results are not sensitive to whether matching or blocking are used.

Sensitivity 2: Dynamic treatment selection Dynamic treatment assignment tends to create a more negative selection into treatment over time, as individuals with 'better' characteristics exit unemployment before receiving treatment. As our treatment refers to vacancies received before the first interview, the treatment effect estimates for those leaving unemployment before the first interview may be subject to unobserved negative selection which may downward bias our estimates. To assess the relevance of this issue, we create a sub-sample of individuals interviewed before 12 weeks in unemployment. Here, the share of unemployed having left unemployment is reduced which is expected to reduce the scope for dynamic treatment selection. At the same time, the timing of vacancy receipt may be earlier on average. ${ }^{19}$

[Insert Figure 7 about here.]

The second row of column of Figure 7 presents the overall and channel-specific effect estimates for the sample of early interviews. Compared to the total sample, the transition effects on the overall and non-PES exit rates are substantially higher, although not significantly so. The differences hence seem to be driven by a higher responsiveness to monitoring among individuals receiving vacancies earlier. Changes in treatment selection over time thus seem to be driven by individuals with lower productivity non-PES search channels, rather than individuals with lower returns to PES search.

\footnotetext{
${ }^{19}$ Table A1 in the Appendix compares the distribution of characteristics for unemployed interviewed before and after 12 weeks. Older people and individuals from East Germany are more likely to be interviewed earlier, otherwise the characteristics of the two groups are very comparable.
} 


\section{Conclusion}

In the regular activation practice, vacancy information is often accompanied by simultaneous monitoring, thus confounding the effect of information provision. Both information and monitoring are expected to increase employment entry, and both may result in the take-up of worse employment types. When measuring the effectiveness of vacancy information it hence is important to disentangle the two mechanisms to be able to devise appropriate policies. Studying the effects of early vacancy information from the PES in Germany, we aim to disentangle the potential interactions between information provision and monitoring. As simultaneous monitoring is not directly observed, we draw on job search theoretic predictions on expected exit patterns by search channel, and test these predictions using information on the successful channel. Finding that vacancy information increases the overall exit rate significantly, we show that this is predominantly driven by an increased take-up of job mediated via the PES. At the same time, the exit rate through non-PES jobs, e.g., jobs found via the internet, social networks, newspaper ads, etc. are temporarily decreased. This is in line with search channels substitution counteracting the effects of vacancy information. In contrast to previous evidence on non-monitored job search (Fougère et al., 2009), we find however that after the initial decrease, the effect on non-PES entry rates becomes positive and then levels out to zero, suggesting that more intensive monitoring counteracts effort substitution. Having documented the presence of monitoring, we conclude that monitoring increases the willingness to apply to the vacancies and limits the costs of effort substitution. Splitting the sample by gender and local labor market conditions, we find very similar monitoring patterns. We find however that the overall benefits of vacancy information are higher for women, and for individuals living in regions with low unemployment rates.

In terms of employment quality we find that vacancy receivers are more likely to accept jobs in temporary work agencies. As TWA vacancies are over-represented at the PES in Germany this can be directly linked to the quality of PES vacancies. We find that the willingness to accept TWA employment may not only be driven by a low productivity of other search channels, but is likely to be enforced by monitoring.

As caseworker may be uncertain about the labor market chances of the unemployed during early unemployment, we suggest that early vacancy information may act as a signaling or screening device for the labor market chances of the unemployed. While it may itself represent a signal of the overall availability of suitable 
vacancies in the labor market, the simultaneous monitoring of the application process may also provide insights about barriers to labor market entry. As caseworker update their beliefs about the reintegration chances for the unemployed, this may affect the choice of ALMP in case the application process is not successful. At best, this may improve both the targeting and matching of costly ALMP programs, and thus affect the medium-run integration chances of the unemployed. Our empirical analysis assesses the effect of vacancy information on ALMP entry rates and whether this mediates the labor market transitions of the unemployed. In the overall sample we do not find any effects on ALMP entry rates. However, we do find that men and unemployed in regions with high unemployment rates have a lower ALMP entry rate in case of continued unemployment. This does not seem to have an effect on labor market transitions, however.

To our knowledge, we are the first to document the reduction of ALMP entry as consequence of early monitoring. The interpretation of this as the result of improved signaling is in line with van den Berg et al. (2013), who suggest that monitoring of vacancy information helps observe and reduce moral hazard in the behavior of the unemployed. Van den Berg et al. (2013) also find that unemployed may be more likely to exit into inactivity (sickness absence) as result of monitoring. This may also lower subsequent ALMP entry. While we cannot assess this reliably with our data, the absence of negative effects in regions with low unemployment and high sanctioning risk suggests that this may not be the driver of our results. Similarly, we do not find effects for women, who are often found more responsive to monitoring by exiting the labor force (e.g. Dolton and O'Neill, 2002). With respect to our methodological approach, the ALMP transition rates could also be influenced by dynamic selection out of unemployment in response to treatment (Vikström, 2015). Note, however that vacancy information is likely to promote employment entry among those who would otherwise not have been able to exit. If there was unobserved dynamic selection, the ensuing distribution of characteristics among vacancy receivers would be expected to be more negative than in the control group. Assuming that ALMP resources focus on those most in need, we would hence expect that vacancy receivers are more likely to enter ALMP. Finding the opposite we suggest that the dynamic selection effect is negligible or that it works against our findings, suggesting that vacancies may have an even more negative effect on ALMP entry.

Observing that ALMP may be used more restrictively after vacancy receipt, we suggest that early vacancy information may improve the cost-effectiveness also for 
those not benefitting from the vacancy in terms of improve integration rates. A direct policy conclusion emerging from our results is that the number and quality of vacancy registrations at the PES should be improved. As vacancy information predominantly affects the higher acceptance of PES jobs, the quality of job matches is a direct function of the vacancy quality. As low coverage rates are considered to be the result of companies distrusting the mediation abilities of the PES (Müller et al., 2011), accompanying policy efforts should thus be directed towards increasing incentives for caseworkers to improve matching between unemployed and caseworker characteristics.

In line with our hypothesis that vacancies act as screening device, a higher registration rate may also improve the counseling quality as caseworkers are better informed about labor market chances or specific hurdles to reintegration. While our findings suggest that vacancy information may reduce the ALMP entries and thus the costs of the overall activation, a cost-neutral improvement of ALMP matching quality may also increase the long-run benefits of the activation process. Clearly, as we are the first to document this relation, our results are difficult to benchmark. Similarly, a more detailed analysis of the mechanism for this ALMP reduction is needed to be able to devise concrete policy conclusions on how to use the signaling power of vacancy information. 


\section{References}

Abbring, J. and G. van den Berg (2003). The Nonparametric Identification of Treatment Effects in Duration Models. Econometrica 71(5), 1491-1517.

Abbring, J. H., G. J. van den Berg, and J. C. van Ours (2005). The Effect of Unemployment Insurance Sanctions on the Transition Rate from Unemployment to Employment. Economic Journal 115(505), 602-630.

Arni, P., R. Lalive, and J. C. Van Ours (2012). How Effective are Unemployment Benefit Sanctions? Looking Beyond Unemployment Exit. Journal of Applied Econometrics 28(7), 1153-1178.

Black, D. A., J. A. Smith, M. C. Berger, and B. J. Noel (2003). Is the Threat of Reemployment Services more Effective Than the Services Themselves? Evidence from Random Assignment in the UI System. American Economic Review 93(4), $1313-1327$.

Boockmann, B., C. Osiander, M. Stops, and H. Verbeek (2013). Effekte von Vermittlerhandeln und Vermittlerstrategien im SGB II und SGB III (Pilotstudie): Abschlussbericht an das IAB durch das Institut für Angewandte Wirtschaftsforschung e. V. (IAW), Tübingen. IAB-Forschungsbericht 201307, Institute for Employment Research (IAB), Nürnberg.

Caliendo, M., A. Falk, L. C. Kaiser, H. Schneider, A. Uhlendorff, G. van den Berg, and K. F. Zimmermann (2011). The IZA Evaluation Dataset: Towards Evidencebased Labor Policy Making. International Journal of Manpower 32(7), 731-752.

Caliendo, M. and S. Kopeinig (2008). Some Practical Guidance For The Implementation Of Propensity Score Matching. Journal of Economic Surveys 22(1), $31-72$.

Caliendo, M., R. Mahlstedt, and O. A. Mitnik (2014, July). Unobservable, but Unimportant? The Influence of Personality Traits (and Other Usually Unobserved Variables) for the Evaluation of Labor Market Policies. IZA Discussion Papers 8337, Institute for the Study of Labor (IZA).

Christensen, B. (2003). Mismatch-Unemployment Among the Low-Skilled. Mitteilungen aus der Arbeitsmarkt- und Berufsforschung 34(4), 506-514.

Cochran, W. G. (1968). The Effectiveness of Adjustment by Subclassification in Removing Bias in Observational Studies. Biometrics 24(2), pp. 295-313.

Crepon, B., G. Jolivet, M. Ferracci, and G. van den Berg (2009). Active Labor Market Policy Effects in a Dynamic Setting. Journal of the European Economic Association 7(2-3), 595-605.

Dehejia, R. H. and S. Wahba (2002). Propensity Score-Matching Methods For Nonexperimental Causal Studies. The Review of Economics and Statistics 84(1), $151-161$.

Dolton, P. and D. O'Neill (2002). The Long-Run Effects of Unemployment Monitoring and Work-Search Programs: Experimental Evidence from the United Kingdom. Journal of Labor Economics 20(2), 381-403. 
Engström, P., P. Hesselius, and B. Holmlund (2012). Vacancy Referrals, Job Search, and the Duration of Unemployment: A Randomized Experiment. Labour 26(4), 419-435.

Fougère, D., J. Pradel, and M. Roger (2009). Does the Public Employment Service Affect Search Effort and Outcomes? European Economic Review 53(7), 846-869.

Fredriksson, P. and P. Johansson (2008). Dynamic Treatment Assignment: The Consequences for EEvaluation Using Observational Data. Journal of Business and Economic Statistics 26(4), 435-445.

Gaynor, J. J., E. J. Feuer, C. C. Tan, D. H. Wu, C. R. Little, D. J. Straus, B. D. Clarkson, and M. F. Brennan (1993). On the Use of Cause-Specific Failure and Conditional Failure Probabilities: Examples From Clinical Oncology Data. Journal of the American Statistical Association 88(422), 400-409.

Goldberg, L. R. (1993). The Structure of Phenotypic Personality Traits. American Psychologist 48(1), 26.

Gorter, C. and G. R. J. Kalb (1996). Estimating the Effect of Counseling and Monitoring the Unemployed Using a Job Search Model. The Journal of Human Resources 31(3), 590-610.

Graversen, B. K. and J. C. van Ours (2008). How to Help Unemployed Find Jobs Quickly: Experimental Evidence from a Mandatory Activation Program. Journal of Public Economics 92(10-11), 2020-2035.

Hainmueller, J., B. Hofmann, G. Krug, and K. Wolf (2015). Do Lower Caseloads Improve the Effectiveness of Active Labor Market Policies? New Evidence from German Employment Offices. Scandinavian Journal of Economics forthcoming.

Hägglund, P. (2014). Experimental Evidence From Active Placement Efforts Among Unemployed in Sweden. Evaluation Review 38(3), 191-216.

Hielscher, V. and P. Ochs (2009). Arbeitslose als Kunden? Beratungsgespräche in der Arbeitsvermittlung zwischen Druck und Dialog. Berlin: edition sigma.

Hofmann, B., G. Krug, F. Sowa, S. Theuer, and K. Wolf (2012). Wirkung und Wirkmechanismen zusätzlicher Vermittlungsfachkräfte auf die Arbeitslosigkeitsdauer Analysen auf Basis eines Modellprojektes. Zeitschrift fuer Evaluation 11(1), 7-38.

Holzer, H. J. (1988). Search Method Use by Unemployed Youth. Journal of Labor Economics 6(1), 1-20.

Huber, M., M. Lechner, and A. Steinmayr (2015). Radius Matching on the Propensity Score with Bias Adjustment: Tuning Parameters and Finite Sample Behavior. Empirical Economics 49(1), 1-31.

Huber, M., M. Lechner, and C. Wunsch (2013). The Performance of Estimators Based on the Propensity Score. Journal of Econometrics 175(1), 1-21.

IAB (2008). Entwicklung des gesamtwirtschaftlichen Stellenangebots vom IV. Quartal 2005 bis zum III. Quartal 2008 in Deutschland. IAB-Erhebung des gesamtwirtschaftlichen Stellenangebots 2005-2008, Bundesagentur für Arbeit. 
Jahn, E. J. and M. Rosholm (2014). Looking Beyond the Bridge: The Effect of Temporary agency Employment on Labor Market Outcomes. European Economic Review 65, $108-125$.

Johnson, T. and D. Klepinger (1994). Experimental Evidence on Unemployment Insurance Work-Search Policies. Journal of Human Resources 29, 695-717.

Kaplan, E. L. and P. Meier (1958). Nonparametric Estimation from Incomplete Observations. Journal of the American Statistical Association 53(282), 457-481.

Kastoryano, S. and B. van der Klaauw (2011). Dynamic Evaluation of Job Search Assistance. IZA Discussion Papers 5424, Institute for the Study of Labor (IZA).

Koppel, O. (2008). Ingenieurarbeitsmarkt in Deutschland - Gesamtwirtschaftliches Stellenangebot und regionale Fachkräftelücken. IW-Trends 35, Institut der Deutschen Wirtschaft Köln.

Kvasnicka, M. (2009). Does Temporary Help Work Provide a Stepping Stone to Regular Employment?, Chapter 10, pp. 335 - 372. Studies of Labor Market Intermediation. University of Chicago Press.

Lechner, M. and C. Wunsch (2013). Sensitivity of Matching-Based Program Evaluations to the Availability of Control Variables. Labour Economics 21, 111-121.

Lee, W.-S. (2011). Propensity Score Matching and Variations on the Balancing Test. Empirical Economics 44, 47-80.

Machin, S. and A. Manning (1999). The Causes and Consequences of Longterm Unemployment in Europe. Volume 3 of Handbook of Labor Economics, Chapter 47, pp. 3085-3139. Elsevier.

Müller, A., M. Rebien, and M. Stops (2011). Einschaltungspotenzial für den Arbeitgeber-Service der Bundesagentur für Arbeit. Ergebnisse aus der IABErhebung des Gesamtwirtschaftlichen Stellenangebots. Stellungnahme 10, IAB.

Müller, K.-U. (2007). Individual and Regional Determinants of Receiving Unemployment Benefit Sanctions in Germany. AStA Wirtschafts- und Sozialstatistisches Archiv 1 (3-4), 275-286.

Müller, K.-U. and F. Oschmiansky (2006). Die Sanktionspolitik der Arbeitsagenturen nach den Hartz-Reformen: Analyse der Wirkungen des Ersten Gesetztes für moderne Dienstleistungen am Arbeitsmarkt. Discussion paper SP I 2006-116, Social Science Research Center Berlin (WZB).

OECD (2007). Employment Outlook. Paris: OECD Publishing.

Pedersen, J. M., M. Rosholm, and M. Svarer (2012). Experimental Evidence on the Effects of Early Meetings and Activation. IZA Discussion Paper 6970, Institute for the Study of Labor (IZA).

Rosenbaum, P. and D. Rubin (1983). The Central Role of the Propensity Score in Observational Studies for Causal Effects. Biometrika 70(1), 41-55.

Rosenbaum, P. R. and D. R. Rubin (1984). Reducing Bias in Observational Studies Using Subclassification on the Propensity Score. Journal of the American Statistical Association 79(387), 516-524. 
Roy, A. (1951). Some Thoughts on the Distribution of Earnings. Oxford Economic Papers 3(2), 135-146.

Rubin, D. B. (1974). Estimating Causal Effects of Treatment in Randomized and Nonrandomized Studies. Journal of Educational Policy 66, 688-701.

Schütz, H., J. Steinwede, H. Schröder, B. Kaltenborn, N. Wielage, G. Christe, and P. Kupka (2011). Vermittlung und Beratung in der Praxis - eine Analyse von Dienstleistungsprozessen am Arbeitsmarkt. IAB-Bibliothek, Biefeld, Bertelsmann.

Smith, J. and P. Todd (2005). Does Matching Overcome LaLonde's Critique of Nonexperimental Estimators? Journal of Econometrics 125(1-2), 305-353.

van den Berg, G. J. (1994). The Effects of Changes of the Job Offer Arrival Rate on the Duration of Unemployment. Journal of Labor Economics 12(3), 478-498.

van den Berg, G. J. (2001). Duration models: Specification, Identification and Multiple Durations. Volume 5 of Handbook of Econometrics, Chapter 55, pp. 33813460. Elsevier.

van den Berg, G. J., A. H. Bergemann, and M. Caliendo (2009). The Effect of Active Labor Market Programs on Not-Yet Treated Unemployed Individuals. Journal of the European Economic Association 7(2-3), 606-616.

van den Berg, G. J., B. Hofmann, and A. Uhlendorff (2013). The Role of Sickness in the Evaluation of Job Search Assistance and Sanctions. mimeo.

van den Berg, G. J. and B. van der Klaauw (2006). Counseling And Monitoring Of Unemployed Workers: Theory And Evidence From A Controlled Social Experiment. International Economic Review 47(3), 895-936.

van den Berg, G. J. and J. C. van Ours (1996). Unemployment Dynamics and Duration Dependence. Journal of Labor Economics 1(1), 100-125.

Vikström, J. (2015). Evaluation of Sequences of Treatment with Application to Active Labor Market Policies. Working Paper 5, IFAU Institute for ehe Evaluation of Labour Market and Education Policy.

Vikström, J., G. Ridder, and M. Weidner (2015). Bounds on Treatment Effects on Transitions. CeMMAP working papers CWP01/15, Centre for Microdata Methods and Practice, Institute for Fiscal Studies.

Vikström, J. (2014). IPW Estimation and Related Estimators for Evaluation of Active Labor Market Policies in a Dynamic Setting. Working Paper 1, IFAU Institute for Labor Market and Education Policy. 


\section{Tables}

Table 1: Theoretical predictions on the effects of vacancy information

\begin{tabular}{lccc}
\hline \hline & \multicolumn{3}{c}{ Outcome } \\
\cline { 2 - 4 } Vacancy information & PES Entry & Non-PES Entry & Employment Quality \\
\hline without monitoring & + & - & $+/-$ \\
with monitoring & ++ & $+/-$ & - \\
\hline \hline
\end{tabular}

Note: Own representation.

Table 2: Sample selection and observation numbers

\begin{tabular}{lrc}
\hline \hline Selection criterion & $\mathrm{N}$ & Percent \\
\hline Full sample & 8,915 & 100.0 \\
Active search & 7,088 & 79.5 \\
UB-receipt & 6,532 & 73.3 \\
Search for full-time employment & 5,534 & 62.1 \\
Older than 25 years & 4,257 & 47.8 \\
Non-missings in relevant information & 4,044 & 45.4 \\
\hline \multicolumn{2}{c}{ Note: Own calculations, based on the IZA Evaluation Dataset $S}$.
\end{tabular}

Table 3: Vacancy receipt by interview timing

\begin{tabular}{lcccccccccc}
\hline \hline Week of the interview & 8 & 9 & 10 & 11 & 12 & 13 & 14 & 15 & 16 & $>16$ \\
\hline $\operatorname{Pr}(D=1)$ & 0.41 & 0.42 & 0.40 & 0.43 & 0.44 & 0.39 & 0.45 & 0.45 & 0.48 & 0.54 \\
$N$ & 626 & 521 & 409 & 435 & 484 & 487 & 304 & 332 & 231 & 218 \\
\hline \hline
\end{tabular}

Note: Own calculations, based on the IZA Evaluation Dataset $S$.

Table 4: Characteristics of first employment spell by treatment indicator

\begin{tabular}{lccc}
\hline \hline & no VI & VI & $t$-test \\
\cline { 2 - 4 } & $(1)$ & $(2)$ & $(3)$ \\
\hline \hline Job found via PES & 0.10 & 0.21 & 0.00 \\
Temporary Work Agency & 0.12 & 0.16 & 0.01 \\
Temporary Employment & 0.39 & 0.39 & 0.95 \\
Hourly wage (Euro) & 8.34 & 8.25 & 0.47 \\
Hours worked & 41.79 & 41.22 & 0.14 \\
\hline $\mathrm{N}$ & 1,382 & 1,147 & \\
\hline \hline
\end{tabular}

Note: Own calculations, based on the sample of unemployed who entered regular employment or ALMP within 13 month of their initial unemployment registrations. 
Table 5: Labor market characteristics and job search information by treatment indicator

\begin{tabular}{|c|c|c|c|}
\hline & no VI & VI & $t$-test \\
\hline & $(1)$ & $(2)$ & $(3)$ \\
\hline \multicolumn{4}{|l|}{ Socio-demographic characteristics } \\
\hline West Germany & 0.633 & 0.740 & 0.000 \\
\hline Female & 0.457 & 0.409 & 0.002 \\
\hline Has a child & 0.449 & 0.436 & 0.575 \\
\hline Married & 0.488 & 0.431 & 0.000 \\
\hline \multicolumn{4}{|l|}{ Age of the respondent } \\
\hline Between 25 and 34 years & 0.323 & 0.355 & 0.034 \\
\hline Between 35 and 44 years & 0.322 & 0.343 & 0.157 \\
\hline Between 45 and 54 years & 0.355 & 0.302 & 0.000 \\
\hline \multicolumn{4}{|l|}{ Vocational education } \\
\hline None & 0.063 & 0.050 & 0.094 \\
\hline Vocational training degree & 0.639 & 0.685 & 0.002 \\
\hline Technical college/university & 0.298 & 0.265 & 0.019 \\
\hline \multicolumn{4}{|l|}{ Employment history } \\
\hline \multicolumn{4}{|l|}{ Employment status before Unemployment } \\
\hline Employed & 0.829 & 0.849 & 0.086 \\
\hline School, Apprentice, Military, etc. & 0.074 & 0.061 & 0.101 \\
\hline Maternity Leave & 0.017 & 0.019 & 0.750 \\
\hline Other & 0.080 & 0.071 & 0.324 \\
\hline \multicolumn{4}{|l|}{ Share of adulthood in... } \\
\hline unemployment & 0.063 & 0.056 & 0.020 \\
\hline employment & 0.705 & 0.731 & 0.008 \\
\hline \multicolumn{4}{|l|}{ Previous unemployment spells } \\
\hline Number of spells & 1.054 & 1.048 & 0.807 \\
\hline Missings in the number of spells & 0.022 & 0.015 & 0.094 \\
\hline Long-term unemployed & 0.249 & 0.221 & 0.039 \\
\hline \multicolumn{4}{|l|}{ Local labor market and ALMP shares } \\
\hline Vacancy rate & 0.008 & 0.009 & 0.019 \\
\hline Unemployment rate & 0.087 & 0.080 & 0.000 \\
\hline Share of unemployed in ALMP & 0.208 & 0.216 & 0.001 \\
\hline \multicolumn{4}{|c|}{ Search behavior and interaction with the PES during unemployment } \\
\hline \multicolumn{4}{|l|}{ Unemployment benefit receipt } \\
\hline Current receipt (yes/no) & 0.782 & 0.819 & 0.003 \\
\hline Level of UB (Euro) & 600.78 & 634.12 & 0.037 \\
\hline \multicolumn{4}{|l|}{ Search intensity } \\
\hline Number of own applications & 14.07 & 16.08 & 0.002 \\
\hline Zero applications & 0.065 & 0.034 & 0.000 \\
\hline Number of search channels & 4.607 & 5.318 & 0.000 \\
\hline \multicolumn{4}{|c|}{ Activation offers by the PES - direct labor market entry } \\
\hline Job in TWA & 0.000 & 0.138 & 0.000 \\
\hline Regular full-time job & 0.000 & 0.915 & 0.000 \\
\hline Regular part-time job & 0.000 & 0.163 & 0.000 \\
\hline Self-Employment Subsidy & 0.063 & 0.068 & 0.561 \\
\hline Job in Marginal Employment & 0.006 & 0.012 & 0.055 \\
\hline Apprenticeship place & 0.003 & 0.006 & 0.175 \\
\hline Placement voucher & 0.075 & 0.111 & 0.000 \\
\hline \multicolumn{4}{|c|}{ Activation offers by the PES - indirect labor market entry or training } \\
\hline One-Euro-Job & 0.007 & 0.019 & 0.000 \\
\hline Job Creation Scheme & 0.006 & 0.012 & 0.081 \\
\hline Work-training & 0.117 & 0.176 & 0.000 \\
\hline Training to improve employability & 0.087 & 0.117 & 0.002 \\
\hline German language course & 0.001 & 0.001 & 0.906 \\
\hline English language course & 0.027 & 0.030 & 0.641 \\
\hline Training voucher & 0.064 & 0.069 & 0.538 \\
\hline Exited unemployment before 1st interview & 0.751 & 0.746 & 0.739 \\
\hline $\mathrm{N}$ & 2,321 & 1,723 & \\
\hline$\%$ & 0.57 & 0.44 & \\
\hline
\end{tabular}

Note: Own calculations. All numbers are shares, unless otherwise indicated. 
Table 6: Summary of balancing quality: $t$-test and standardized bias. Entry Sample and Employment Sample

\begin{tabular}{ccccccc}
\hline & \multicolumn{3}{c}{ Total Sample } & \multicolumn{3}{c}{ Employment Sample } \\
& Sample & Treated & Controls & Sample & Treated Controls \\
\cline { 2 - 7 } & $(1)$ & $(2)$ & $(3)$ & $(4)$ & $(5)$ & $(6)$ \\
\hline \multicolumn{3}{c}{ Number of characteristics with $p$-value } & & & \\
\hline less than 0.01 & 18.00 & 0.00 & 0.00 & 19.00 & 0.00 & 0.00 \\
less than 0.05 & 32.00 & 0.00 & 0.00 & 26.00 & 0.00 & 0.00 \\
less than 0.10 & 45.00 & 0.00 & 0.00 & 33.00 & 0.00 & 0.00 \\
less than 0.20 & 57.00 & 0.00 & 0.00 & 46.00 & 0.00 & 0.00 \\
less than 0.30 & 65.00 & 0.00 & 0.00 & 59.00 & 0.00 & 1.00 \\
less than 0.40 & 76.00 & 0.00 & 1.00 & 65.00 & 1.00 & 4.00 \\
less than 0.50 & 87.00 & 0.00 & 5.00 & 74.00 & 2.00 & 11.00 \\
less than 0.60 & 94.00 & 10.00 & 14.00 & 78.00 & 6.00 & 26.00 \\
less than 0.70 & 101.00 & 22.00 & 27.00 & 84.00 & 23.00 & 39.00 \\
less than 0.80 & 107.00 & 50.00 & 51.00 & 86.00 & 42.00 & 58.00 \\
less than 0.90 & 112.00 & 75.00 & 87.00 & 92.00 & 75.00 & 77.00 \\
less than 1 & 117.00 & 117.00 & 117.00 & 102.00 & 102.00 & 102.00 \\
\hline Mean MSB & 5.08 & 0.75 & 0.75 & 6.07 & 0.99 & 0.99 \\
\hline \hline
\end{tabular}

Table 7: Summary of balancing quality: $t$-test and standardized bias. Employment Sample

\begin{tabular}{|c|c|c|c|}
\hline & $\begin{array}{c}\text { Unmatched } \\
\text { Sample }\end{array}$ & $\begin{array}{c}\text { Matched to } \\
\text { Treated }\end{array}$ & $\begin{array}{c}\text { Matched to } \\
\text { Controls }\end{array}$ \\
\hline & $(1)$ & $(2)$ & $(3)$ \\
\hline \multicolumn{4}{|c|}{ Number of characteristics with $p$-value } \\
\hline less than 0.01 & 19.00 & 0.00 & 0.00 \\
\hline less than 0.05 & 26.00 & 0.00 & 0.00 \\
\hline less than 0.10 & 33.00 & 0.00 & 0.00 \\
\hline less than 0.20 & 46.00 & 0.00 & 0.00 \\
\hline less than 0.30 & 59.00 & 0.00 & 1.00 \\
\hline less than 0.40 & 65.00 & 1.00 & 4.00 \\
\hline less than 0.50 & 74.00 & 2.00 & 11.00 \\
\hline less than 0.60 & 78.00 & 6.00 & 26.00 \\
\hline less than 0.70 & 84.00 & 23.00 & 39.00 \\
\hline less than 0.80 & 86.00 & 42.00 & 58.00 \\
\hline less than 0.90 & 92.00 & 75.00 & 77.00 \\
\hline less than 1 & 102.00 & 102.00 & 102.00 \\
\hline Mean MSB & 6.07 & 0.99 & 0.99 \\
\hline \multicolumn{4}{|c|}{$\begin{array}{l}\text { Note: We used kernel matching on the propensity score with an } \\
\text { Epanechnikov kernel and optimal bandwidth that was selected } \\
\text { to minimize the difference in characteristics in the matched sam- } \\
\text { ple. Varying numbers of variables may arise due to differential } \\
\text { use of interaction terms. }\end{array}$} \\
\hline
\end{tabular}


Table 8: Treatment effects: employment characteristics of first employment spell

\begin{tabular}{lrrrrr}
\hline \hline & Total & Women & Men & $\begin{array}{r}\text { Low } \\
\text { Unemp }\end{array}$ & $\begin{array}{r}\text { High } \\
\text { Unemp }\end{array}$ \\
\cline { 2 - 6 } TWA & $\mathbf{3 . 4 0}$ & $\begin{array}{r}0.60 \\
(1.40)\end{array}$ & $\begin{array}{r}\mathbf{4 . 9 0} \\
(1.78)\end{array}$ & $\begin{array}{r}1.00 \\
(1.97)\end{array}$ & $\begin{array}{r}\mathbf{4 . 3 0} \\
(1.96)\end{array}$ \\
\hline \multirow{2}{*}{ Short-term work } & $\begin{array}{r}1.20 \\
(1.86)\end{array}$ & $\begin{array}{c}0.30 \\
(3.17)\end{array}$ & $\begin{array}{r}1.40 \\
(2.27)\end{array}$ & $\begin{array}{r}1.50 \\
(2.58)\end{array}$ & $\begin{array}{r}0.00 \\
(2.84)\end{array}$ \\
\hline \multirow{2}{*}{ Hourly wage } & -0.18 & -0.28 & 0.01 & -0.14 & -0.13 \\
& $(0.11)$ & $(0.18)$ & $(0.14)$ & $(0.15)$ & $(0.14)$ \\
\hline \multirow{2}{*}{ Hours worked } & $\mathbf{- 0 . 7 7}$ & -0.10 & $\mathbf{- 1 . 3 7}$ & $\mathbf{- 0 . 9 5}$ & -0.75 \\
& $(0.38)$ & $(0.60)$ & $(0.45)$ & $(0.42)$ & $(0.46)$ \\
\hline \hline
\end{tabular}

Note: Treatment effect estimates are obtained by kernel matching (see Section 5). Standard errors are given in the parentheses. They are obtained by bootstrapping with 199 replications. Bold numbers indicate significance at the $5 \%$-level. 


\section{Figures}

Figure 1: Survival Functions for Employment and ALMP transitions

Employment Entry

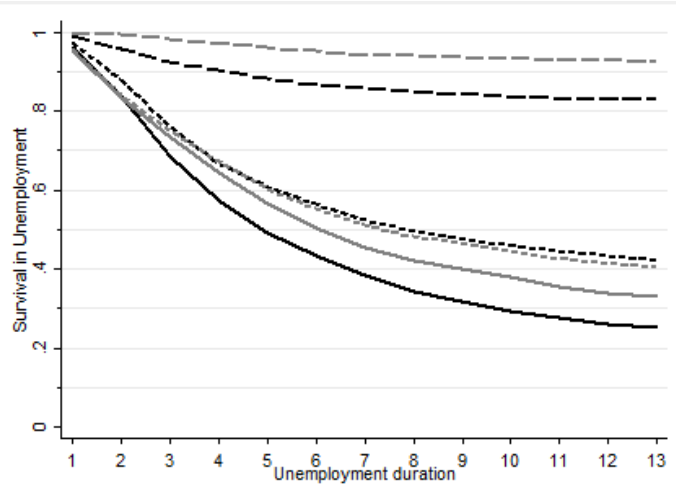

ALMP Entry

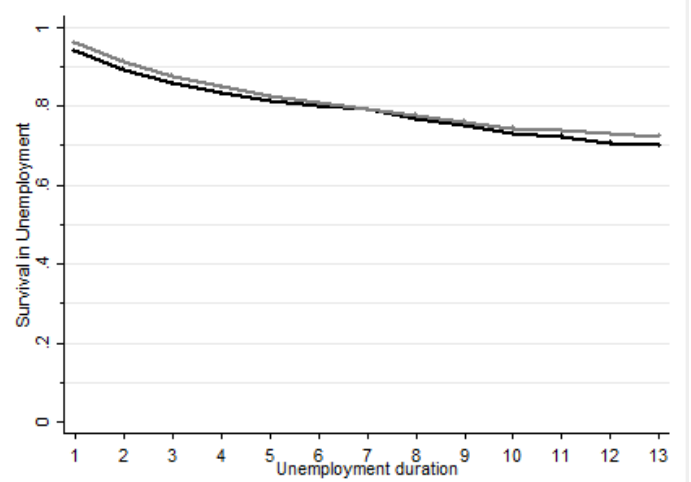

Note: Own calculations. Black (gray) lines indicate survival functions for the treated (non-treated).

Solid lines in the left panel indicate overall employment entry rates. Long (short) dashed lines indicate entry due to PES (non-PES) channels.

Figure 2: Treatment effects: employment transitions overall and channel-specific
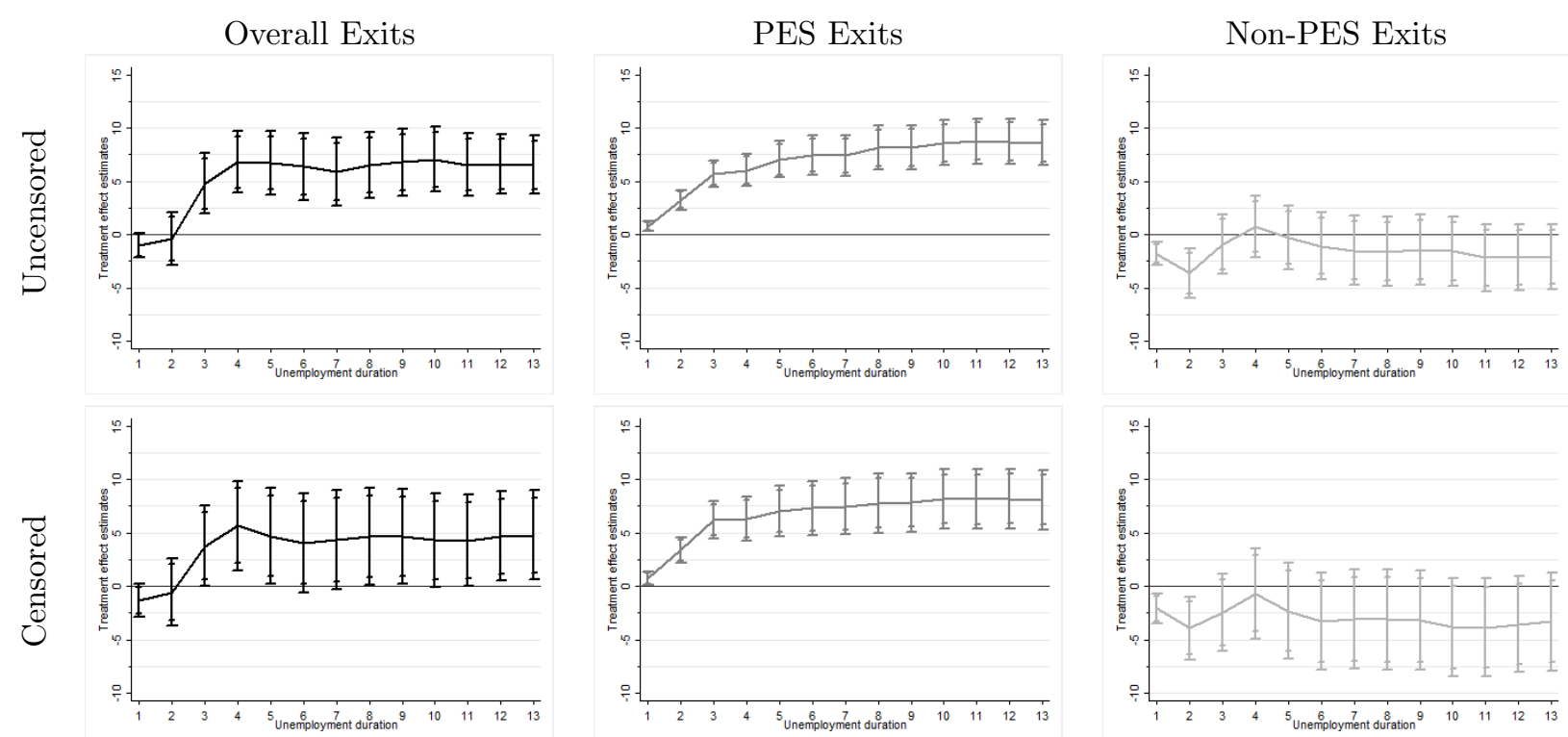

Note: Treatment effect estimates for the overall and channel-specific exit rates are obtained by kernel matching on the propensity score. Uncensored estimates do not account for subsequent ALMP entry. Censored estimates do not include unemployed who entered ALMP using the weighting correction outline in Section 5. PES exits refer to jobs found via the PES, their online information system or subsidized private placement agencies. Non-PES exits refer to jobs found via the newspaper ads, friends and family, the internet, un-subsidized placement agencies, the internet or other channels. Vertical lines depict confidence intervals, with small (large) caps representing the $90 \%$ (95\%) confidence bands. Standard errors are obtained by bootstrapping with 199 replications. 
Figure 3: Heterogeneity analysis: employment transitions by gender

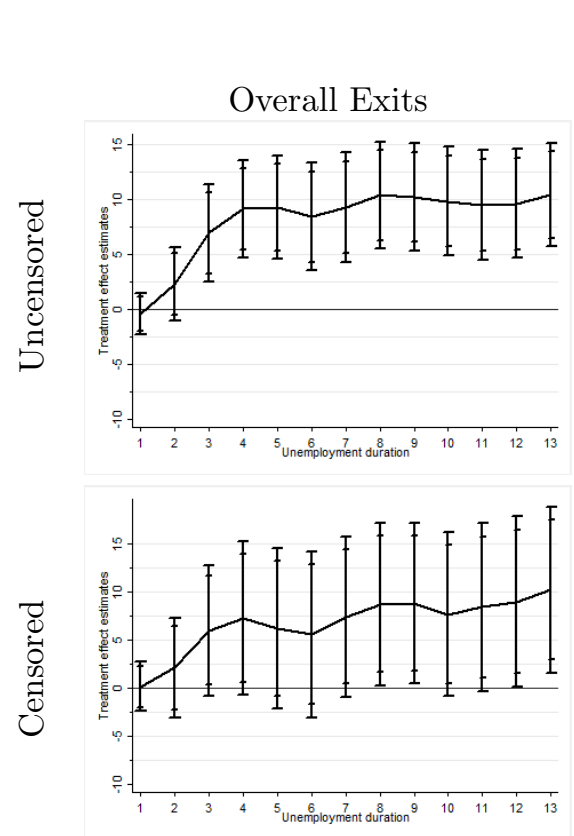

Women
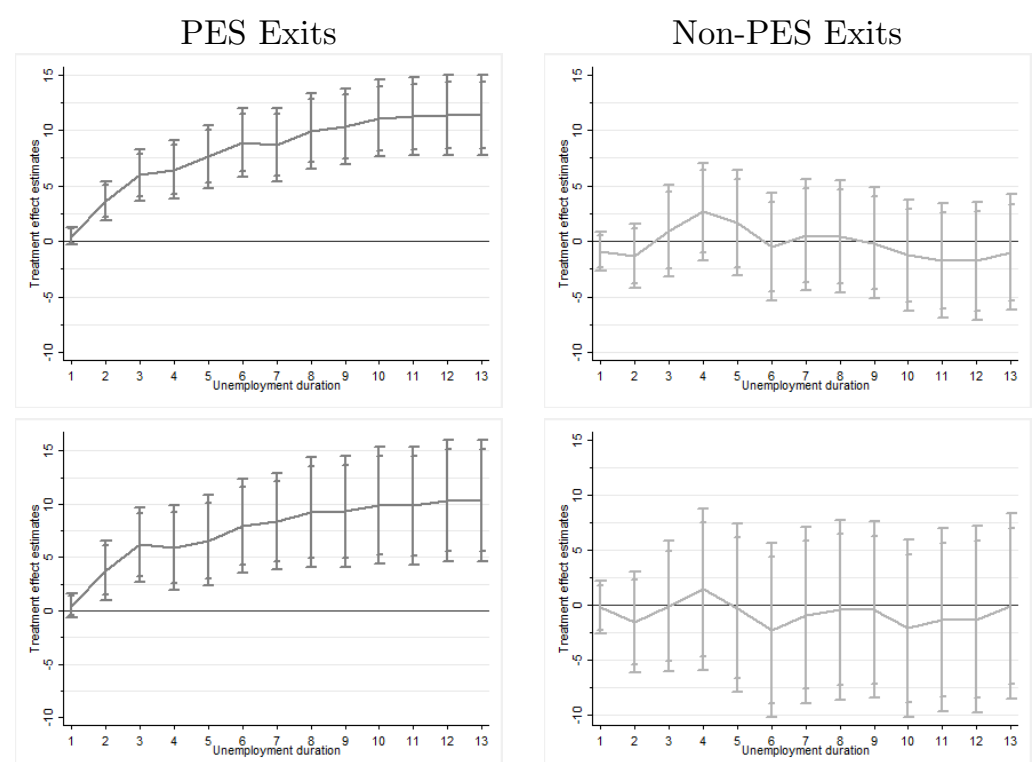

Men
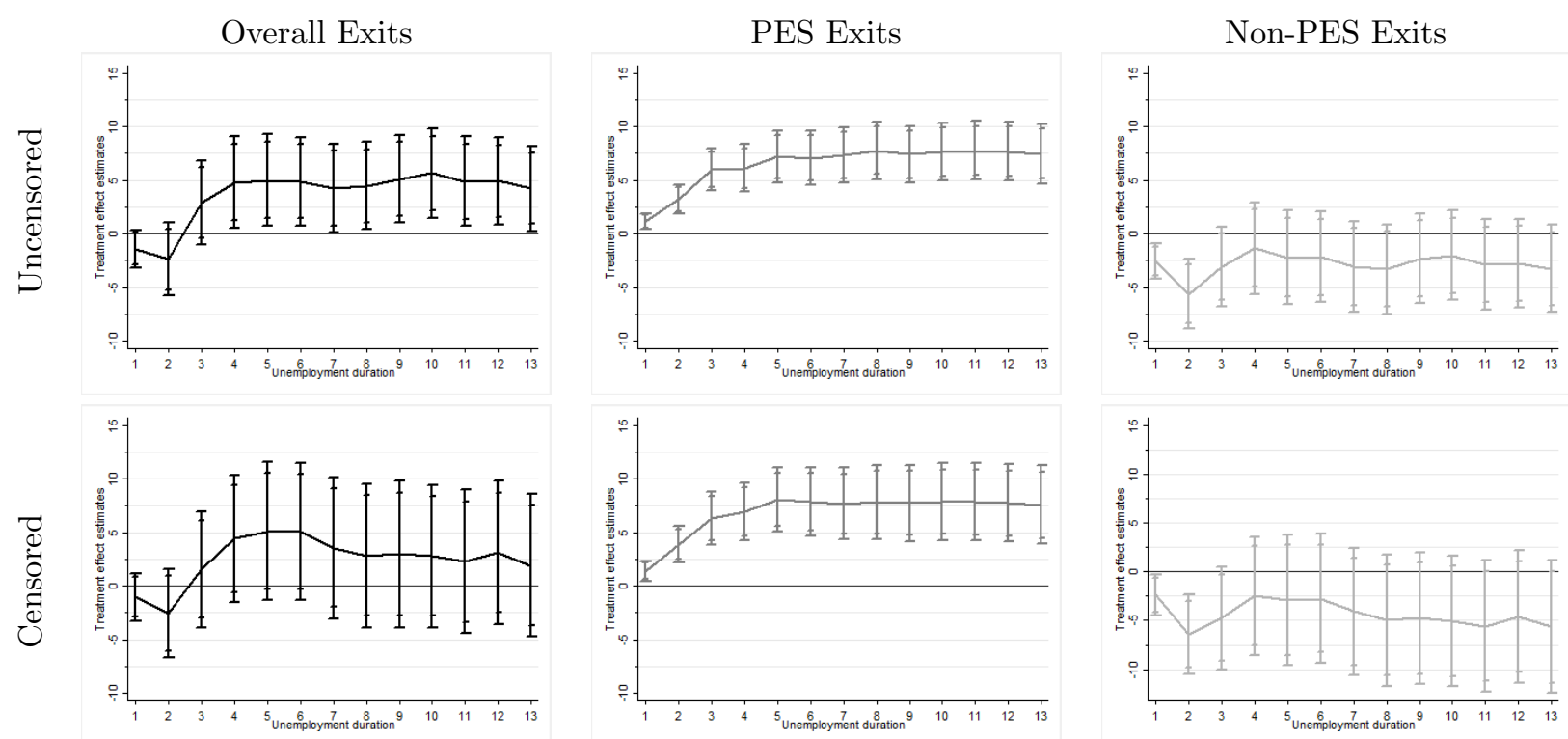

Note: Treatment effect estimates for the overall and channel-specific exit rates are obtained by kernel matching on the propensity score. Uncensored estimates do not account for subsequent ALMP entry. Censored estimates do not include unemployed who entered ALMP using the weighting correction outline in Section 5. PES exits refer to jobs found via the PES, their online information system or subsidized private placement agencies. Non-PES exits refer to jobs found via the newspaper ads, friends and family, the internet, un-subsidized placement agencies, the internet or other channels. Vertical lines depict confidence intervals, with small (large) caps representing the $90 \%$ (95\%) confidence bands. Standard errors are obtained by bootstrapping with 199 replications. 
Figure 4: Heterogeneity analysis: employment transitions by labor market conditions

Low unemployment rates
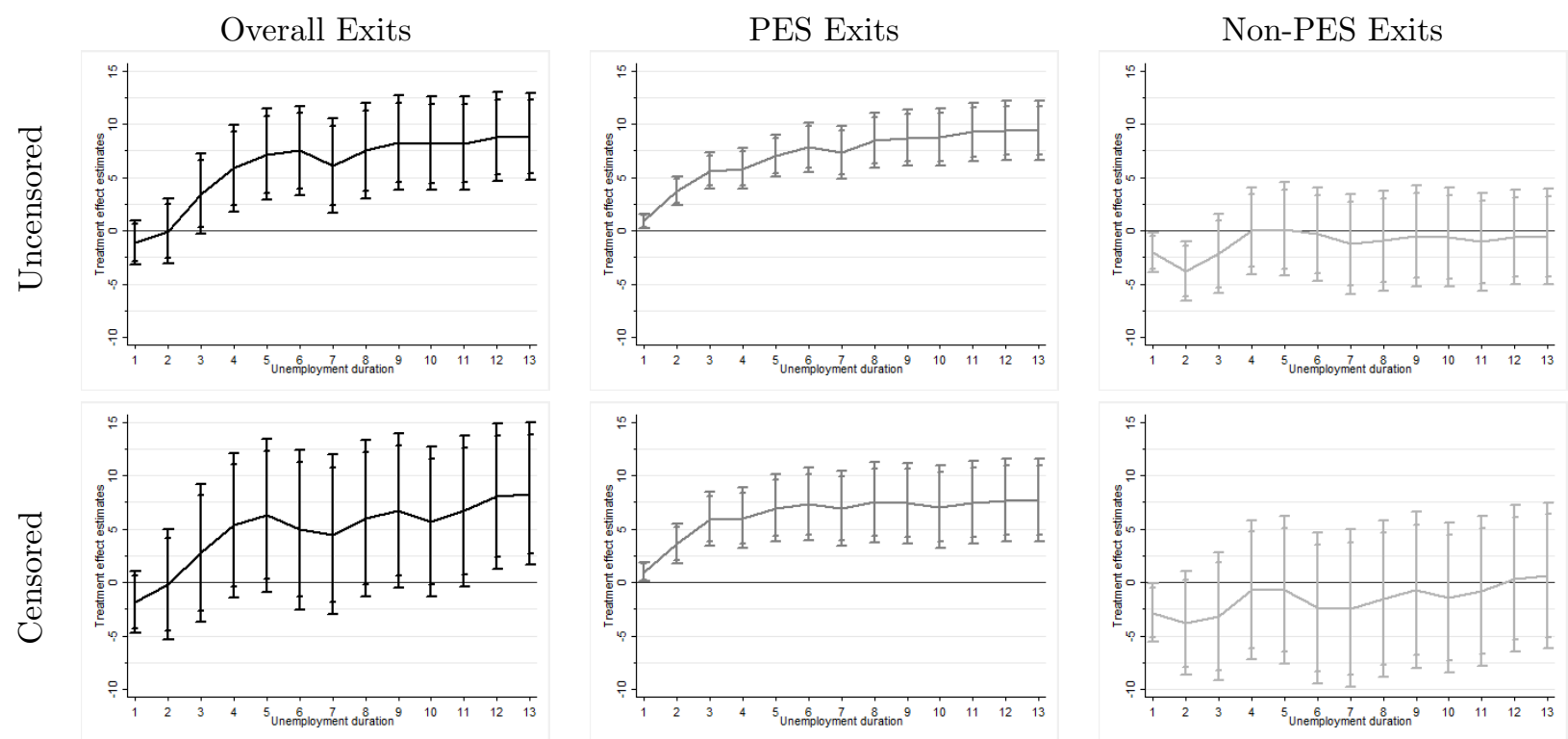

High unemployment rates

Overall Exits
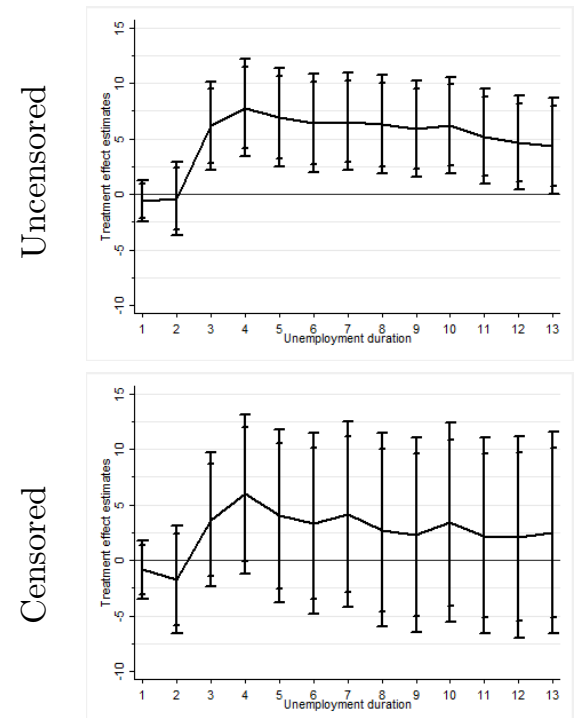

PES Exits
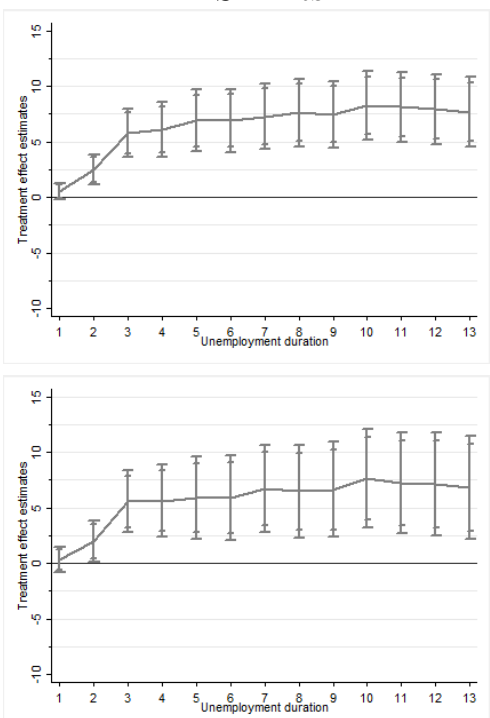

Non-PES Exits
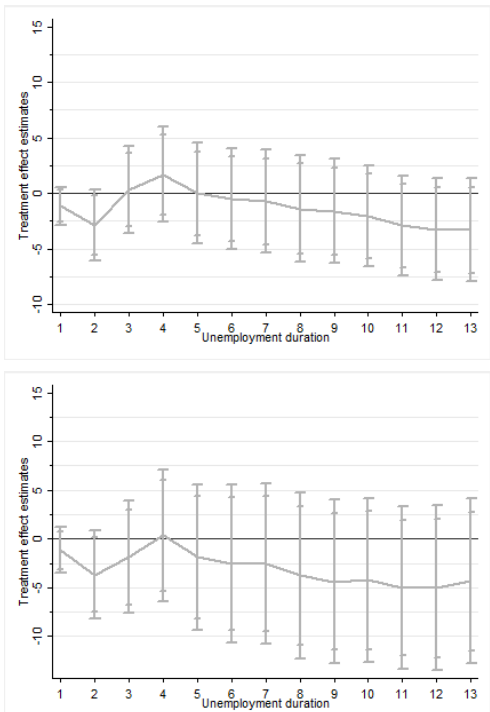

Note: Treatment effect estimates for the overall and channel-specific exit rates are obtained by kernel matching on the propensity score. Uncensored estimates do not account for subsequent ALMP entry. Censored estimates do not include unemployed who entered ALMP using the weighting correction outline in Section 5. PES exits refer to jobs found via the PES, their online information system or subsidized private placement agencies. Non-PES exits refer to jobs found via the newspaper ads, friends and family, the internet, un-subsidized placement agencies, the internet or other channels. Low vs. high unemployment rates are distinguished by the median unemployment rate at point of interview (approx. $7 \%$ ). Vertical lines depict confidence intervals, with small (large) caps representing the $90 \%$ (95\%) confidence bands. Standard errors are obtained by bootstrapping with 199 replications. 
Figure 5: Treatment effects:

\section{ALMP transition}

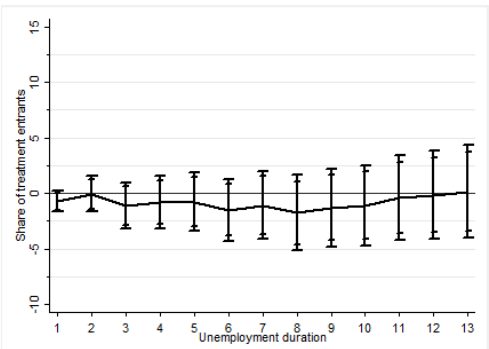

Note: Treatment effect estimates for the negative effect on survival until exit into ALMP are obtained by kernel matching. Vertical lines depict confidence intervals, with small (large) caps representing the $90 \%$ (95\%) confidence bands. Standard errors are obtained by bootstrapping with 199 replications.

Figure 6: Heterogeneity analysis: ALMP transitions by gender and labor market conditions

Women

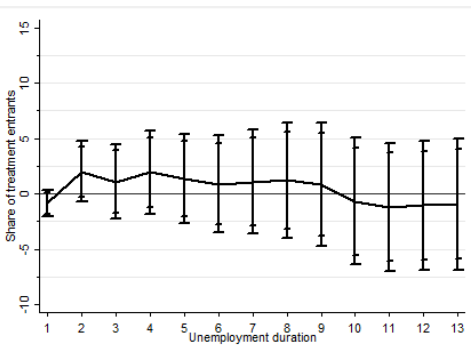

Low Unemployment

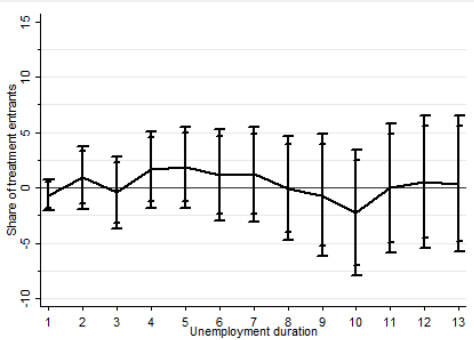

Men

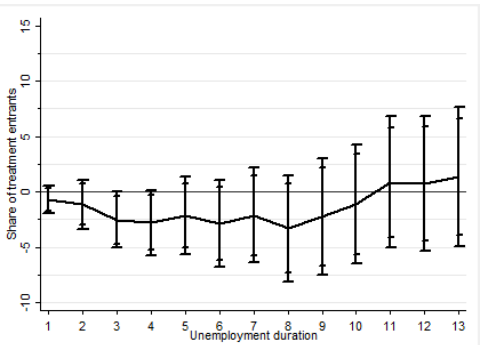

High Unemployment

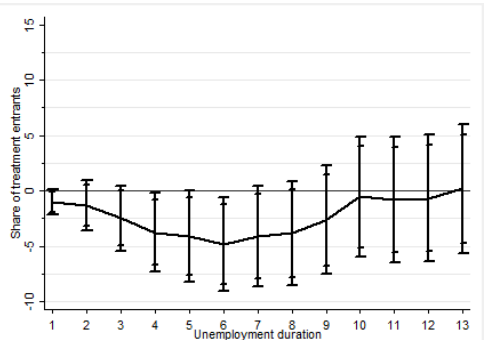

Note: Treatment effect estimates for the negative effect on survival until exit into ALMP are obtained by kernel matching. Vertical lines depict confidence intervals, with small (large) caps representing the $90 \%$ (95\%) confidence bands. Standard errors are obtained by bootstrapping with 199 replications. Low vs. high unemployment rates are distinguished by the median unemployment rate at point of interview (approx. $7 \%$ ). 
Figure 7: Sensitivity Analysis: Blocking and Early Interviews

Total Exits
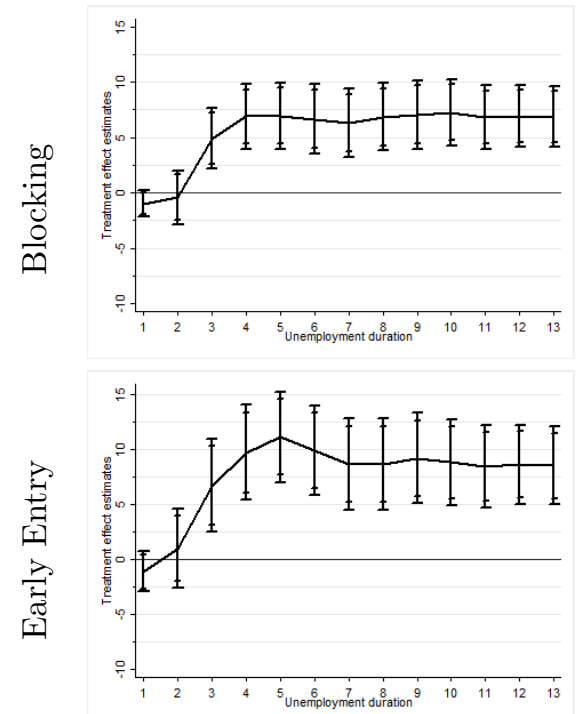

PES Exits
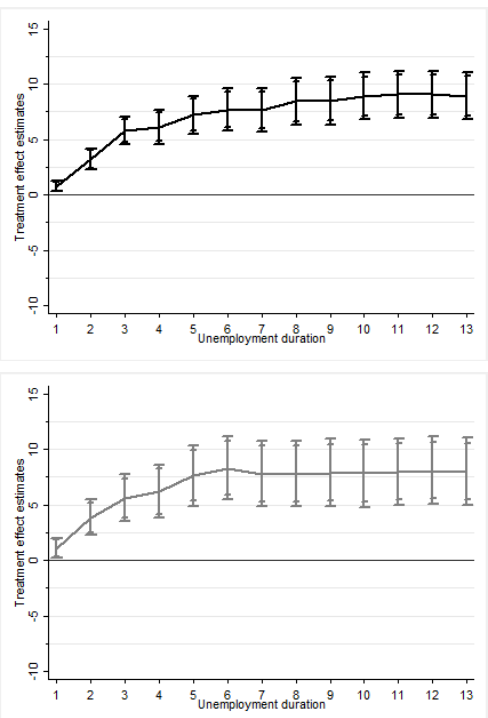

Non-PES Exits
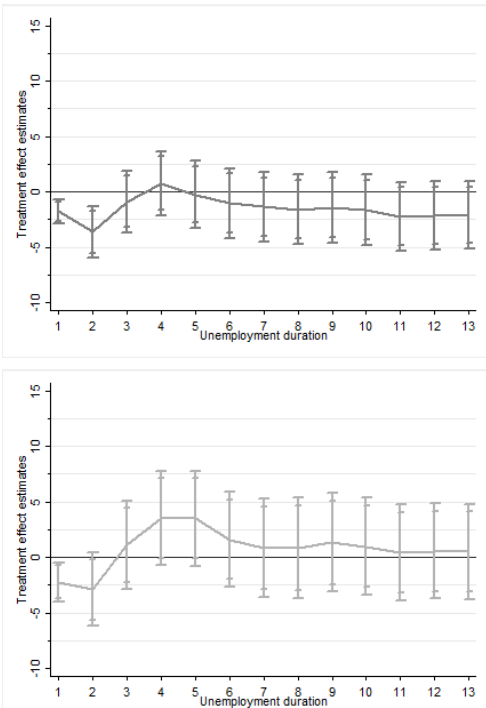

Note: Treatment effect estimates in the first row are obtained by blocking on the propensity score using 5 blocks. Treatment effect estimates in the second row are obtained by kernel matching on the propensity score, restricting the sample to individuals who were interviewed before 12 weeks in unemployment. All exit rates are uncensored. Vertical lines depict confidence intervals, with small (large) caps representing the $90 \%$ (95\%) confidence bands. Standard errors are obtained by bootstrapping with 199 replications. 


\section{Appendix}

Table A1: Labor market characteristics and job search information by timing of interview

\begin{tabular}{|c|c|c|c|}
\hline & $\begin{array}{c}\text { Interview } \\
\text { after } 12 \text { weeks }\end{array}$ & $\begin{array}{c}\text { Interview } \\
\text { before } 12 \text { weeks }\end{array}$ & $t$-test \\
\hline & $(1)$ & $(2)$ & $(3)$ \\
\hline West Germany & 0.715 & 0.660 & 0.000 \\
\hline Female & 0.422 & 0.444 & 0.185 \\
\hline Has a child & 0.445 & 0.442 & 0.892 \\
\hline Married & 0.465 & 0.463 & 0.886 \\
\hline \multicolumn{4}{|l|}{ Age of the respondent } \\
\hline Between 25 and 34 years & 0.369 & 0.320 & 0.002 \\
\hline Between 35 and 44 years & 0.320 & 0.336 & 0.310 \\
\hline Between 45 and 54 years & 0.311 & 0.344 & 0.034 \\
\hline \multicolumn{4}{|l|}{ Vocational education } \\
\hline None & 0.059 & 0.057 & 0.764 \\
\hline Vocational training degree & 0.658 & 0.659 & 0.983 \\
\hline Technical college/university & 0.283 & 0.285 & 0.894 \\
\hline \multicolumn{4}{|l|}{ Employment status before Unemployment } \\
\hline Employed & 0.799 & 0.857 & 0.000 \\
\hline School, Apprentice, Military, etc. & 0.085 & 0.060 & 0.003 \\
\hline Maternity Leave & 0.020 & 0.017 & 0.460 \\
\hline Other & 0.096 & 0.066 & 0.001 \\
\hline \multicolumn{4}{|l|}{ Employment history } \\
\hline \multicolumn{4}{|l|}{ Share of adulthood in... } \\
\hline unemployment & 0.058 & 0.061 & 0.299 \\
\hline employment & 0.700 & 0.724 & 0.021 \\
\hline \multicolumn{4}{|l|}{ Previous unemployment spells } \\
\hline Number of spells & 1.043 & 1.056 & 0.599 \\
\hline Missings in the number of spells & 0.022 & 0.018 & 0.342 \\
\hline Long-term unemployed & 0.229 & 0.241 & 0.406 \\
\hline \multicolumn{4}{|l|}{ Local labor market and ALMP shares } \\
\hline Vacancy rate & 0.009 & 0.008 & 0.000 \\
\hline Unemployment rate & 0.082 & 0.085 & 0.013 \\
\hline Share of unemployed in ALMP & 0.210 & 0.212 & 0.693 \\
\hline \multicolumn{4}{|l|}{ Activation offers by the PES } \\
\hline \multicolumn{4}{|l|}{ Direct labor market entry } \\
\hline Job in TWA & 0.068 & 0.054 & 0.078 \\
\hline Regular full-time job & 0.413 & 0.378 & 0.033 \\
\hline Regular part-time job & 0.071 & 0.069 & 0.788 \\
\hline Self-Employment Subsidy & 0.059 & 0.068 & 0.265 \\
\hline Job in Marginal Employment & 0.010 & 0.009 & 0.732 \\
\hline Apprenticeship place & 0.004 & 0.004 & 0.871 \\
\hline Placement voucher & 0.109 & 0.081 & 0.004 \\
\hline \multicolumn{4}{|l|}{ Indirect labor market entry or training } \\
\hline One-Euro-Job & 0.018 & 0.009 & 0.020 \\
\hline Job Creation Scheme & 0.007 & 0.009 & 0.541 \\
\hline Work-training & 0.141 & 0.143 & 0.906 \\
\hline Training to improve employability & 0.104 & 0.097 & 0.462 \\
\hline German language course & 0.002 & 0.001 & 0.208 \\
\hline English language course & 0.024 & 0.030 & 0.303 \\
\hline Training voucher & 0.067 & 0.066 & 0.957 \\
\hline Exited unemployment before 1st interview & 0.654 & 0.797 & 0.000 \\
\hline $\mathrm{N}$ & 1352 & 2692 & \\
\hline
\end{tabular}

Note: Own calculations. All numbers are shares, unless otherwise indicated. 